\title{
Neuropsychiatric diagnosis and management of chronic sequelae of war-related mild to moderate traumatic brain injury
}

\author{
Joshua D. Halbauer, MD; ${ }^{1-3}$ J. Wesson Ashford, MD, PhD; ${ }^{1-3^{*}}$ Jamie M. Zeitzer, PhD; ${ }^{1-3}$ Maheen M. Adamson, \\ PhD; ${ }^{1-3}$ Henry L. Lew, MD, PhD; ${ }^{1,4}$ Jerome A. Yesavage, MD $^{1-3}$ \\ ${ }^{1}$ Department of Veterans Affairs (VA) Palo Alto Health Care System, Palo Alto, CA; ${ }^{2}$ VA, Sierra-Pacific Mental Illness \\ Research, Education and Clinical Center and War-Related Illness and Injury Study Center, Palo Alto, CA; \\ ${ }^{3}$ Department of Psychiatry and Behavioral Sciences, Stanford University School of Medicine, Stanford University, CA; \\ ${ }^{4}$ Physical Medicine and Rehabilitation, VA Boston Healthcare System, Boston, MA
}

\begin{abstract}
Soldiers with a traumatic brain injury (TBI) present with an array of neuropsychiatric symptoms that can be grouped into nosological clusters: (1) cognitive dysfunctions: difficulties in memory, attention, language, visuospatial cognition, sensorymotor integration, affect recognition, and/or executive function typically associated with neocortical damage; (2) neurobehavioral disorders: mood, affect, anxiety, posttraumatic stress, and psychosis, as well as agitation, sleep problems, and libido loss, that may have been caused by damage to the cortex, limbic system, and/or brain stem monoaminergic projection systems; (3) somatosensory disruptions: impaired smell, vision, hearing, equilibrium, taste, and somatosensory perception frequently caused by trauma to the sensory organs or their projections through the brain stem to central processing systems; (4) somatic symptoms: headache and chronic pain; and (5) substance dependence. TBI-related cognitive impairment is common in veterans who have served in recent conflicts in the Middle East and is often related to blasts from improvised explosive devices. Although neurobehavioral disorders such as depression and posttraumatic stress disorder commonly occur after combat, the presentation of such disorders in those with head injury may pass undetected with use of current diagnostic criteria and neuropsychological instruments. With a multidimensional approach (such as the biopsychosocial model) applied to each symptom cluster, psychological, occupational, and social dysfunction can be delineated and managed.
\end{abstract}

Key words: affective, aggression, agitation, attention, communication, executive function, language, memory, pain, PTSD, rehabilitation.

\section{INTRODUCTION}

Through the introduction of advanced warfare technologies, soldier mortality from bullets and bomb blasts has decreased [1]. Soldiers are instead sustaining increased

Abbreviations: AAN = American Academy of Neurology, ACRM = American Congress of Rehabilitation Medicine, $\mathrm{AD}=$ Alzheimer disease, $\mathrm{ADHD}=$ attention deficit hyperactivity disorder, APOE = apolipoprotein E, DSM-III = Diagnostic and Statistical Manual of Mental Disorders (DSM)-Third Edition, DSM-IVTR = DSM-Fourth Edition-Text Revision, DTI = diffusion tensor imaging, FA $=$ fractional anisotropy, FDA $=$ Food and Drug Administration, ICD-10 = International Classification of Diseases-10th Edition, $\mathrm{LOC}=$ loss of consciousness, MNI $=$ mild neurocognitive impairment, NMDA $=\mathrm{N}$-methyl-D-aspartate, $\mathrm{OEF}=$ Operation Enduring Freedom, OIF = Operation Iraqi Freedom, PCD = postconcussion disorder, PCS = postconcussion syndrome, PDGMC = personality disorder due to a general medical condition, PTA = posttraumatic amnesia, PTSD = posttraumatic stress disorder, QOL = quality of life, ROI = region of interest, $\mathrm{RR}=$ risk ratio, $\mathrm{SSRI}=$ selective serotonergic reuptake inhibitor, TBI = traumatic brain injury, VA = Department of Veterans Affairs, WMLL = white matter load lesion.

*Address all correspondence to J. Wesson Ashford, MD, PhD; War-Related Illness and Injury Study Center, VA Palo Alto Health Care System, 151-W, 3801 Miranda Ave, Palo Alto, CA 94304; 650-852-3287; fax: 650-852-3297.

Email: wes.ashford@va.gov

DOI:10.1682/JRRD.2008.08.0119 
head, face, and neck injuries, particularly traumatic brain injuries (TBIs) [2]. Identifying areas of functional, cognitive, and psychiatric impairments in those with TBI from these conflicts has presented a variety of challenges. Various organizations, such as the American Congress of Rehabilitation Medicine (ACRM), the American Academy of Neurology (AAN), and the American Psychiatric Association, have different diagnostic classifications that delineate specific factors directly related to TBI and its long-term sequelae. These classifications are limited in many respects and present challenges for diagnosis and, ultimately, treatment. These classifications will be discussed in terms of their nosology, possible underlying neurobiology, applicability, and utility for patient treatment, particularly from a psychopharmacological perspective.

Although TBI is caused by physical head trauma, the chronic sequelae of TBI are defined in terms of clusters of neuropsychiatric symptoms (Figure 1): (1) cognitive dysfunctions (memory, attention, language, visuospatial cognition, sensory-motor integration, affect recognition, and executive function), (2) neurobehavioral disorders (mood, affect, anxiety, posttraumatic stress, psychotic, sleep, and libidinal disorders), (3) somatosensory disruptions (changes in smell, vision, hearing, equilibrium, taste, and somatosensory perception), (4) somatic symptoms (headache, chronic pain), and (5) substance dependence. This article will examine incidence, prevalence, neurobiological bases, diagnostic criteria, and brief instruments for assessing these symptom clusters and then provide clinicians with approaches for neuropsychiatric treatment. Furthermore, with this organizational approach applied to patients with TBI, impairments found in particular aspects of daily functioning (e.g., reduced employment, impaired social relationships, and decreased quality of life [QOL]) [3] can be identified and referred for psychosocial interventions.

A prior study examined TBI from a similar multifactorial perspective but found little "high-class" evidence on which to base any treatment recommendations for patients with TBI [4]. In contrast, the current formulation with use of neurobiological understanding is based on parsing symptoms into common nosological classifications not usually associated with TBI and on borrowing from the extensive experience with those related disorders for developing treatment options. The applicable common diagnostic entities include Alzheimer disease (AD), posttraumatic stress disorder (PTSD), depression, and attention deficit hyperactivity disorder (ADHD). In addition, the formulation presented in this review is based on evidence that neuroplastic systems exist in the brain for self-repair and adaptation after brain injury; furthermore, extensive evidence suggests that numerous interventions can facilitate these repair mechanisms even if memory function is impaired. Accordingly, a broad array of reasonable treatments exists that can be applied to managing the chronic sequelae of TBI.

This review will emphasize the recognition of the types of problems commonly seen in other disorders that are associated with TBI and then discuss the application of the many specific psychopharmacological treatments that have been demonstrated to have substantial efficacy in those related conditions to the treatment of patients with TBI. This review will mention rehabilitative, neuropsychological, and behavioral treatment options, but a full review of these is beyond the scope of this discussion.

\section{CURRENT SYSTEMS OF CLASSIFICATION OF TBI SEQUELAE}

Current classifications of TBI-related problems correspond only roughly with the actual conditions and long-term outcomes. These classifications (delineated in the following list) generally relate to the acute TBI, particularly the presentation and symptoms apparent in the first 24 hours after the TBI, have not been based on longitudinal observational studies [5], and provide little reliable evidence for an association between clinical factors and outcome [6]. For example, the International Classification of Diseases-10th Edition (ICD-10) lists the following relevant codes:

- F06.8: Other specified mental disorders due to brain damage and dysfunction and to physical disease index.

- F07.2: Postconcussion syndrome (PCS).

- F50-F59: Behavioral syndromes associated with physiological disturbances and physical factors.

- G90-G99: Other disorders of the nervous system.

- S06.0: Concussion.

Clearly, these classifications do not adequately cover the complex problems that often result from TBI. Some other classifications that have been applied to patients who have suffered TBI are provided in the following sections.

\section{TBI Severity}

A primary concern in treating a patient with a TBI is determining the severity of the injury. Injury severity depends on a variety of factors related to the nature of the 


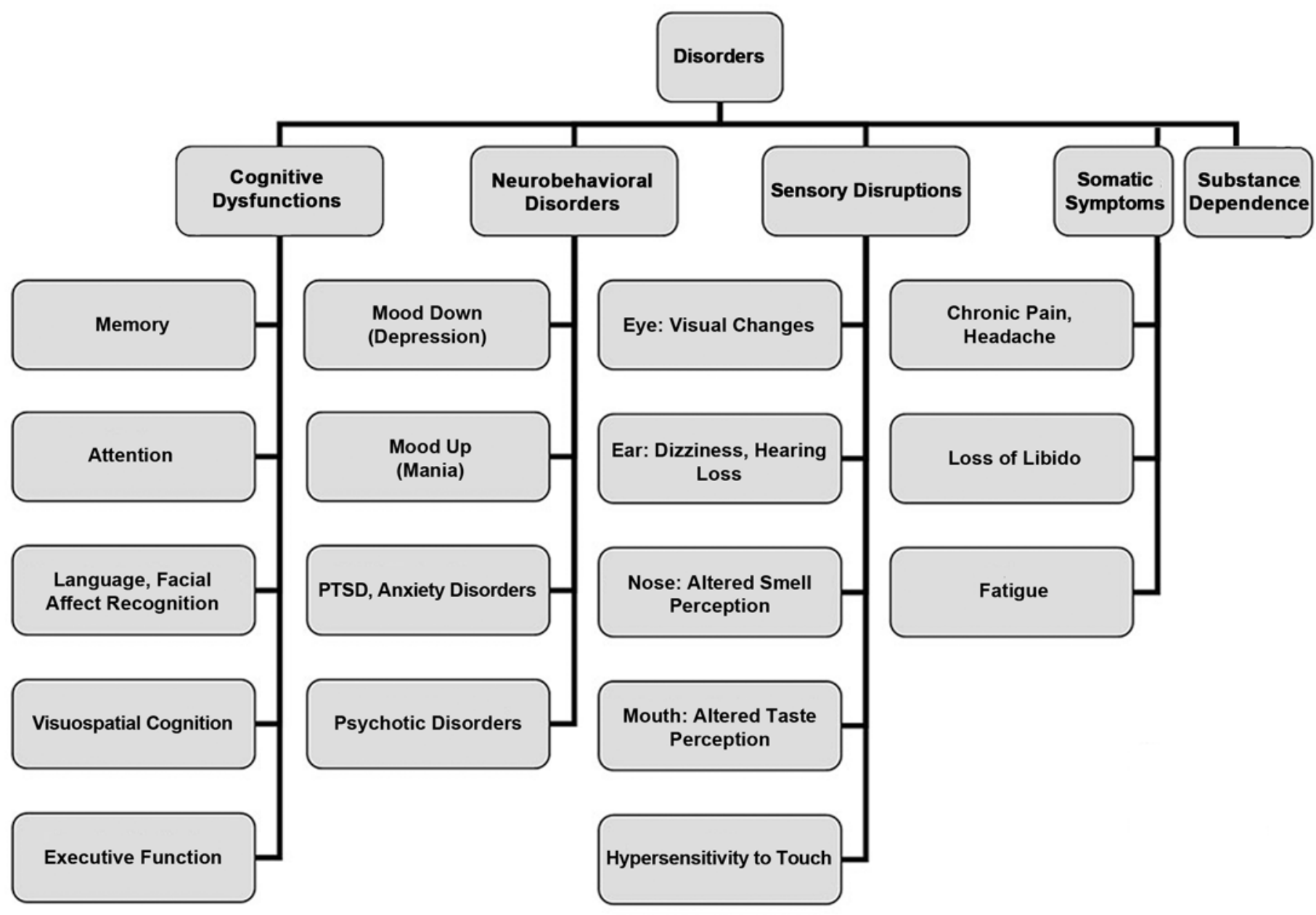

Figure 1.

Clusters of neuropsychiatric symptoms of traumatic brain injury. PTSD = posttraumatic stress disorder.

physical force that caused the injury and the condition of the individual at the time of receiving the assault. The physical force that causes an injury can be single or complex, come from any direction and include secondary repercussions, and consist of an energy shock wave that traverses the brain or an object that penetrates the skull. Examples of complexities that make TBI unique are-

- Individual head attributes-age, skull thickness, protective gear, etc.

- Brain reserve (cognitive, neuronal), prior injury history.

- Individual repair mechanisms (e.g., genetics-apolipoprotein E [APOE] genotype).

- Type of injury, nonpenetrating, penetrating (may not be noted).

- Direction of physical force impacting head.

- Orientation/location of force-translational vs rotational.
- Nature of physical energy — amplitude, risetime, wavelength, duration, reflection.

- Effects on brain-brain stem, cortex, white matter.

- Complexity—multiplicity of injury, contusion, bleeding, infection.

- Psychological stress, social imperatives.

- Immediate care after injury-observation, medication, intervention.

- Chronic care after injury-rehabilitation, support.

Furthermore, many premorbid psychological factors influence an individual's short- and long-term response to TBI. The acute severity of a TBI is initially classified according to the individual's immediate responses, including loss of consciousness (LOC) and posttraumatic amnesia (PTA). One must realize, however, that the severity of the acute phase, related to damage of specific brain 
regions such as the brain stem or the medial temporal lobe, may only loosely predict many other problems that can develop weeks and years later for an individual with a TBI. These complexities lead to the conclusion that every TBI has a unique pattern of presentation and sequelae.

A definition of mild TBI developed by the ACRM [7] states that a person with mild TBI is one who has traumatically induced changes as manifested by at least one of the following:

1. Any period of LOC for less than $30 \mathrm{~min}$ and a Glasgow Coma Scale score of 13 to 15.

2. Any loss of memory of events (PTA) immediately before or after the accident and not exceeding $24 \mathrm{~h}$.

3. Any alteration in mental state at the time of the accident (e.g., feeling dazed, disoriented, or confused).

4. Focal neurological deficits.

The ACRM also lists a number of other physical, cognitive, and behavioral symptoms as further evidence that mild TBI has occurred, including nausea, dizziness, vomiting, headache, disturbed vision, decreased concentration, fatigue, lethargy, memory loss, irritability, and emotional lability. However, these signs and symptoms are not adequately parsed into factors relating to the many different types of specific damage that can occur within the skull and how they relate to acute concerns versus long-term sequelae.

\section{Posttraumatic Amnesia}

Part of the ACRM diagnosis of TBI depends on the duration of PTA. The duration of PTA is a good marker for acutely estimating whether TBI is moderate to severe and especially predicts short-term prognosis when the presenting individual is seen early in the course of PTA and when the time of the injury is known [8]. However, the duration of PTA is unlikely to be observed in a combat arena, and this measure (when potential observers may be fighting for their own lives or be even more severely injured) has not been demonstrated to be a reliable marker for predicting the extent of impairment in mild TBI cases [9]. The lack of sensitivity of PTA in mild TBI may be due to the conditions that make mild TBI difficult to evaluate even within 24 hours of the injury: (1) the lack of a lower limit of PTA [7], which creates a situation in which an individual can have PTA without it being observable or measurable [10-11], and (2) the lack of test-retest stability (patients are difficult to assess, their levels fluctuate, the available measures of memory are poor) within a 24-hour time scale with use of the commonly available neuro- psychological scales, such as the Westmead PTA Scale [12], the Galveston Orientation and Amnesia Test [13], or the Julia Farr Centre PTA Scale [14].

\section{White Matter Integrity}

Defining the neuropathology associated with persistent cognitive deficits in mild TBI is problematic. Frequently, no demonstrable abnormalities can be found on standard magnetic resonance imaging brain scans [15]. An objective assessment of neuropathology may be achieved with use of diffusion tensor imaging (DTI). DTI measures fractional anisotropy (FA), which relates to the diffusion of hydrogen atoms in particular directions at specific points. The FA can be used for tractography, generating white matter fiber tract maps [16]. FA is believed to reflect many factors, including the degree of myelination and axonal density or integrity [17-20].

Kraus et al. proposed a "white matter lesion load" (WMLL) score, a measure of the total number of regions with reduced FA, as an index of white matter integrity [16]. WMLL is calculated as the total number of regions of interest (ROIs), which show impaired white matter relative to values from controls. The value of WMLL ranged from 0 to 13 (based on examination of 13 ROIs). WMLL was then compared with the results of psychometric testing. Results demonstrated that mild TBI showed reduced white matter integrity in the superior longitudinal fasciculus, sagittal striatum, and corticospinal tracts. Reduced WMLL was greatest in groups with moderate to severe TBI and least in the controls, while individuals with mild TBI fell between these two groups and were significantly different than controls. In cases with moderate to severe TBI, reduction in both radial and axial diffusivity was observed in both the whole brain and in specific ROIs. These findings reflect damage to both myelin and axons. In mild TBI, radial diffusivity was relatively intact while axial diffusivity was increased, suggesting axonal damage; however, irreversible damage to myelin is less common in mild than moderate and severe TBI. In terms of cognitive function, patients with moderate to severe TBI differed significantly from controls in almost all measures of cognitive function, but patients with mild TBI, as a group, did not differ significantly from controls in any neuropsychological domain scores. The authors concluded that certain injuries classified as mild based on TBI variables, such as LOC, may actually be closer (based on actual brain injury) to moderate TBI in the degree of neuropathology. The authors proposed that DTI is a more sensitive delineator of TBI severity and may 
help explain the discrepancies between clinically diagnosed injury severity and cognitive outcome. An additional consideration is that mild TBI is associated with considerable heterogeneity, particularly since variations in where white matter injuries occur will cause dysfunction only related to whether a critical pathway was disrupted, so group predictions cannot be made.

\section{Concussion}

The AAN defines the severity of TBI based on a 5-point concussion scale. In grade I, the individual is confused temporarily without any evidence of memory changes, while in grade II, a brief period of disorientation is followed by anterograde amnesia of $<5 \mathrm{~min}$. In grades III through V, both anterograde amnesia and retrograde amnesia are present. Grades III through V are differentiated on the duration of LOC, with each having PTA $<5$ min for grade III, 5-10 min for grade IV, and $>10$ min for grade V. This system of classification has limitations similar to those of PTA, and the recommended time frame $(1,5$, or $10 \mathrm{~min})$ has even more limited reliability under combat conditions for the lower grades of concussion. The proposed gradations of acute injury, which are likely to be related to brain stem and medial temporal lobe injury, are not clearly related to how numerous other cerebral regions and structures may have been affected.

\section{TBI-Related Sequelae}

\section{Postconcussion Syndrome}

The World Health Organization ICD-10 requires the presence of three or more of the following eight symptoms for classification as PCS: (1) headache; (2) dizziness; (3) fatigue; (4) irritability; (5) insomnia; (6) concentration or (7) memory difficulty; and (8) intolerance of stress, emotion, or alcohol. The criteria for PCS are complex, define no time-interval parameters, and include somatic symptoms and cognitive impairment that distinguish it from the syndromes that only involve behavioral symptoms [21]. Furthermore, the pathophysiological nature of PCS remains controversial. In 175 individuals ( 90 with mild TBI, 85 controls), the diagnosis of PCS had low specificity for mild TBI (43.3\% of patients with mild TBI met criteria, as did $43.5 \%$ of controls) [22]. The authors concluded that the use of the term PCS may be misleading because it may incorrectly suggest that the basis of PCS is clearly attributable to a grossly observable brain injury. High rates of PCS have been reported in both nondisabled populations [23-26] and non-brain-injured patients [27-28]. Analyses of PCS patients have found that a previous history of affective or anxiety disorders (including PTSD), being female, a higher IQ (intelligence quotient), and pain significantly predicted acute PCS. No difference was found in neuropsychological test performance between patients with mild TBI and controls, with or without defined PCS. Acute pain appeared to moderate acute outcome in mild TBI, and symptoms were more apparent in those individuals with mild TBI comorbid with PTSD than those without comorbid PTSD [29]. While TBI may indeed have a unique role in causing PCS, the common association of PCS with other types of trauma decreases its value as an index of TBI severity or a prognostic indicator of TBI outcome.

\section{Neuropsychiatric Sequelae}

The Diagnostic and Statistical Manual of Mental Disorders-Fourth Edition-Text Revision (DSM-IV-TR) [30] of the American Psychiatric Association has several different classifications that a clinician can use to describe neuropsychiatric sequelae following TBI. Multiple psychiatric disorders listed in DSM-IV-TR may be found in patients with TBI and classified with descriptions attributing the disorders to TBI: "Delirium due to a general medical condition," "Dementia due to a specific cause," "Amnesic disorder due to a specific cause," "Mood disorder due to a specific cause," "Anxiety disorder due to a specific cause," "Psychotic disorder due to a specific cause," etc. A recent review of TBI-related noncognitive psychiatric disorders (depression, mania, PTSD, psychosis, agitation, and aggression) found significant gaps in the literature on post-TBI psychiatric conditions with respect to nosology, epidemiology, and risk factors [21]. Several of these conditions will be discussed here. However, three classifications are particularly relevant for framing a discussion of the changes that occur in patients related to mild and moderate TBI:

1. Mild neurocognitive impairment (MNI): As defined in Appendix B of the DSM-IV-TR, MNI describes cognitive dysfunction and encompasses the cognitive domains of memory, attention, language, speed of processing, perceptual and motor abilities, and executive function [30]. A diagnosis of MNI requires support of neuropsychological testing (criterion $\mathrm{C}$ ), and all individuals presenting with cognitive complaints should receive clinically appropriate neuropsychological testing. MNI diagnostic criteria have been adopted by $\mathrm{AD}$ researchers and have been expanded to better characterize individuals whose impairments do not meet criteria for dementia but suggest increased risk of developing dementia in the near 
term. MNI classification is based on the number and type of cognitive domains affected and the neuropsychological test results. For a single cognitive-domain impairment that is memory-related in nature, the diagnosis is "mild cognitive impairment," and a nonmemoryrelated single cognitive- domain impairment diagnosis is defined as "single mild nonmemory related cognitive impairment." If two or more cognitive domains are affected, regardless of the nature of the affected domains, the diagnosis is MNI. Following a diagnosis of MNI, the list or type specifiers are useful for treatment.

2. Personality disorder due to a general medical condition (PDGMC): This condition is an axis I diagnosis (personality disorder independently is an axis II diagnosis). Personality traits may be defined as an enduring pattern of how we perceive our environment, how we think about it, and how we relate to it. General diagnostic criteria for this disorder require two of the following domains to be affected: cognition, affectivity, interpersonal functioning, and impulse control. Deficits must be enduring and pervasive and affect social and occupational functioning. PDGMC is limited in its applicability because its reference to cognitive dysfunction is listed only in general terms: "cognition-i.e., ways of perceiving and interpreting self and others." This diagnosis does not define impairments in the cognitive domains of attention, memory, language, visuospatial abilities, sensory-motor skills, or executive function. Specifiers are also listed in general terms (labile, disinhibited, aggressive, apathetic, paranoid, combined, etc.) and do not relate directly to cognition but instead to affectivity and impulse control. Personality disorders are also generally thought of as "untreatable" conditions that require intensive psychotherapy and for which limited pharmaceutical or medical options exist; personality issues are not well managed by medical specialties in general. Clinicians applying this diagnosis may incorrectly attribute mood or affect problems to this syndrome alone, thus missing the indication to treat an underlying depression or other disorder. Furthermore, when applying the "personality disorder stigma," clinicians may also overlook individual cognitive domains. Rather than focusing on personality issues that are poorly defined neurobiologically, this review addresses those psychiatric disorders that are relatively common in patients with TBI, have been identified in the general population, and have associated treatment options.
3. Postconcussion disorder (PCD): This disorder is a DSMIV-TR Appendix B-based diagnosis. Criterion A requires three of the following to occur shortly after the trauma for at least 3 months: fatigue; disturbed sleep; headache; vertigo or dizziness; irritability or aggression; anxiety, depression, or affect lability; changes in personality; and apathy or lack of spontaneity. Criterion B of PCD only addresses attention and memory-type cognitive deficits and does not mention domains such as language, visuospatial, or sensory-motor cognition. Criterion C lists "depression, anxiety, personality changes" that overlap criterion B and also depression and anxiety syndromes. To address the complex needs of a patient with TBI, clinicians need to fully characterize and diagnose depression and anxiety so that these components can be appropriately treated and not simply be dismissed as a component of PCD. Somatic symptoms such as hypersensitivity to sound and touch are common symptoms that need to be examined and integrated into the diagnosis and management.

\section{Clinical Biopsychosocial Approach to TBI}

Traumatic injury is understood as causing a multisystem condition interfering with the functioning of multiple organs and systems, even with those not directly related to the site of the initial impact [31]. If a multidimensional approach (such as the biopsychosocial model) is followed, the many overlapping symptoms and outcomes from combatsustained injuries can be delineated and successfully treated. Applying the biopsychosocial model (a systems model addressing biological, psychological, and social approaches to diagnosis and treatment that is widely used in modern psychiatry) to each symptom cluster, clinicians can delineate and manage psychological, occupational, and social dysfunction in combat veterans.

The brain is composed of numerous systems, and one part may be selectively injured and another not. While neurobehavioral and cognitive dysfunctions probably represent an interruption of circuitry involving the cortex and subcortical structures, somatosensory symptoms are most likely due to damage of specific sensory organs or their projections. Frequently, no clear evidence exists to establish a link between a specific cognitive dysfunction and specific somatic symptoms. Dizziness, for example, may be associated with memory impairment in one individual and with language difficulties in another. Peripheral damage can also be caused by TBI. For example, animals exposed to isolated, controlled cortical-impact TBI show moderate histopathological changes in the lung and liver, 
which may represent a migration of immunocompetent cells to peripheral organs, potentially leading to their dysfunction [31]. Therefore, identifying the TBI symptom clusters (Figure 1) is essential: cognitive dysfunctions (memory, attention, language, visuospatial cognition, sensory-motor integration, affect recognition, and executive function), neurobehavioral disorders (mood, affect, anxiety, posttraumatic stress, psychotic, sleep and libidinal disorders), somatosensory disruptions (changes in smell, vision, hearing, equilibrium, taste, and somatosensory perception), and somatic symptoms (headache, chronic pain), and substance dependence. Each of these clusters of problems can be dealt with appropriately. In so doing, the primary care physician can coordinate a team to address the biopsychosocial problems comprehensively, recognizing the specific impairments and needs of the patient with TBI, to foster rehabilitation and better long-term function.

Further understanding the underlying neurobiology of TBI can help recognize problems and plan treatments appropriate to the problems. Neural mechanisms in many regions of the brain have neuroplastic properties and are able to reestablish connections [32], though correct restoration of function is probably more difficult and requires more targeted reinnervation [33]. Neuroplastic processes can be utilized in recovery and rehabilitation, but their instability may also lead to deterioration, as may occur in AD and many types of dementia [34]. Furthermore, specific genetic factors, such as APOE genotype, may affect the capacity of neuroplastic processes to repair the brain [35-37]. The ultimate issue is the impact of the patient's biological and psychological problems on social function, which must be included in the diagnostic considerations and management plans.

\section{NEUROPSYCHIATRIC SYMPTOMS AND MANAGEMENT}

The following review of specific neuropsychiatric manifestations of symptom clusters following TBI generally outlines the types of difficulties that are likely to be encountered in a clinical setting. The discussion is divided into five parts:

1. Cognitive dysfunctions.

2. Neurobehavioral disorders.

3. Somatosensory disruptions.

4. Somatic symptoms.

5. Substance dependence.
Each aspect is considered in terms of definition and neurobiological basis, which includes some discussion of known epidemiology; criteria and assessment, which addresses the established diagnostic criteria, brief bedside assessments, and formal psychological and neuropsychological testing; and treatment options, including a discussion of formal evidence and recommendations for evidence-based practice, when available, and practical clinical recommendations. The review introduces the neuropsychiatric management of patients with post-TBI, emphasizing that much study still needs to be done to improve the care of patients with TBI-related problems. We focus on neurobiology and psychopharmacology and summarize treatment considerations (Figures 2 and 3). Cognitive therapeutic approaches and general rehabilitation are not discussed in detail, because their complexities are beyond the scope of this review. Important to note is that such therapeutic intervention must be considered individually, keeping the patient's medical and psychiatric history in mind.

\section{Cognitive Dysfunctions}

The International Classification of Functioning, Disability and Health describes higher-level cognitive functioning as, "Specific mental functions especially dependent on the frontal lobes of the brain, including complex goaldirected behaviors such as decision making, abstract thinking, planning and carrying out plans, mental flexibility, and deciding which behaviors are appropriate under what circumstances; often called executive functions. . . . functions of abstraction and organization of ideas; time management, insight and judgement; concept formation, categorization and cognitive flexibility" [38]. TBI may affect any of these functions. Though cognitive dysfunction is a common complaint, its nature and prevalence are unclear, partly because of the difficulties inherent in designing schema for classifying such conditions [4]. Measurement and quantification of cognition are problematic since cognition is neither a single entity nor ability. Cognitive functions are constructs, and their conceptualization and assessment are constrained by the tools used to measure them. Furthermore, trauma to the central nervous system can be diffuse and does not respect neuroanatomical boundaries or system classifications, thus adding further complexity to the process of evaluation. While neurocognitive deficits and neurobehavioral disorders frequently follow TBI, such problems vary according to specific TBI impact sites and the intensities and unique physical properties of the traumatic force [39], as well as 


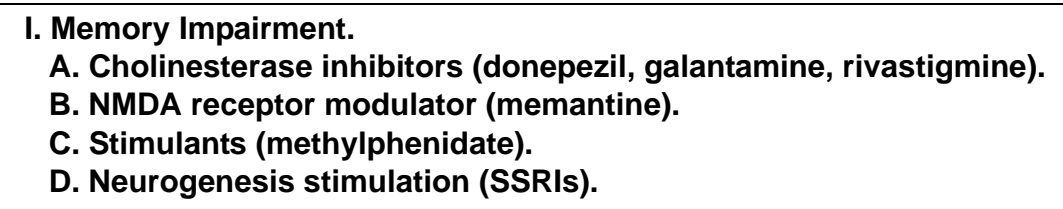

II. Attention Deficits.

A. Texas Medication Algorithm Project. 1. Stimulants (methylphenidate, dextroamphetamine).

2. Noradrenergic reuptake inhibitor (atomoxetine).

3. Bupropion.

4. Alpha-2 agonists (clonidine).

B. Other stimulants (modafinil).

C. Cholinesterase inhibitors (donepezil, galantamine, rivastigmine).

D. NMDA receptor modulator (memantine).

E. Noncompetitive NMDA receptor antagonists (amantadine).

F. Dopamine receptor agonist (bromocriptine).

III. Communication: Linguistics-Speech and Language (Primary Treatment-Speech and Language Therapy).

A. Monoaminergic agents (bromocriptine, levodopa, d-amphetamine).

B. Cholinesterase inhibitors (donepezil, galantamine, rivastigmine).

C. Nootropic agents (piracetam).

D. Experimental-repetitive transcortical magnetic stimulation.

IV. Communication: Affect Recognition and Emotion Expression-Comparison to Autism, No Pharmacological Recommendations.

V. Visuospatial Perception and Sensory-Motor Integration-Behavioral Training Programs.
A. Neurogenesis promoters (SSRIs, lithium).
B. Cholinesterase inhibitors (donepezil, galantamine, rivastigmine).

VI. Executive Function.
A. Dopamine receptor agonist (bromocriptine).
B. Treatment of individual cognitive domains.
C. Treatments developed for attention deficits (see II Attention Deficits).

Figure 2.

Neuropsychiatric symptoms and psychopharmacological management for cognitive dysfunctions. NMDA = N-methyl-D-aspartate, SSRI = selective serotonergic reuptake inhibitor.

the premorbid intellectual status of the patient and the nature of subsequent treatment and rehabilitation. An approach to organizing the wide range of cognitive symptoms that can occur after TBI is summarized in Figure 2. Specific cognitive dysfunctions discussed here are memory, attention, language, visuospatial cognition, sensory-motor integration, and executive function.

\section{Memory}

Definition and Neurobiological Basis. Problems with memory are among the most frequent dysfunctions and complaints following TBI [4]. However, the exact incidence and prevalence of various disorders of memory that are TBI-related are unknown because of the complex relationship between location and severity of TBI and the resulting impairments.
Memory is the foundation for all cognitive function, and memory mechanisms are intricately involved in many cognitive operations. Memory has many modes and delineations. Memory types are frequently specified as (1) implicit or nondeclarative memory, which is responsible for automatic priming (including semantic memory), and (2) explicit or declarative memory storage. This former mode of memory processing is responsible for semantic memory (words), and the latter includes autobiographical memory (memory in context of time and place).

Declarative memory can be divided into separate categories as "working memory" and "long-term storage." Working memory (also referred to as immediate or shortterm memory or attentive memory) allows one to hold in mind, simultaneously, several items needed for performing a task. Working memory is closely associated with systems 

I. Depression.
A. SSRIs (citalopram, sertraline, paroxetine, fluoxetine).
B. SNRIs (duloxetine, venlafaxine).
C. Tricyclics with noradrenergic predominance (nortriptyline, desipramine).
D. Other antidepressants (mirtazapine, bupropion).
E. Stimulants (methylphenidate, dextroamphetamines).

II. Mania.
A. Mood stabilizers (lithium).
B. Mood stabilizers, anticonvulsants (valproate, carbamazepine, oxcarbazepine, topiramate, and lamotragine).
C. Atypical antipsychotics (aripiprazole, olanzapine, ziprazadone, and quietapine).
D. Combinations of medications (including low-dose lithium).

III. Posttraumatic Stress Disorder.
A. SSRIs (citalopram, sertraline, paroxetine, fluoxetine).
B. Serotonin-5HT2 agonist-trazodone (especially for sleep).
C. Noradrenergic alpha-1 blockers-prazosin (especially for sleep).
D. Noradrenergic beta-blockers centrally acting-propranolol.
E. Atypical neuroleptics with serotonergic effects (quetiapine, olanzapine, aripiprazole, and ziprazadone).
F. Avoid typical neuroleptic agents (haloperidol).
G. Avoid sedative hypnotics (benzodiazepines).

IV. Psychosis.
A. Atypical neuroleptics (quetiapine, olanzapine, risperidone, etc.).
B. Typical neuroleptic agents (haloperidol).

V. Agitation and Aggression.
A. Beta-blockers with central effects (propranolol).
B. Alpha-2 antagonist (clonidine).
C. Stimulants (methylphenidate, dextroamphetamines).
D. SSRIs (citalopram, sertraline, paroxetine, and fluoxetine).
E. Tricyclic antidepressants (especially low doses of doxepin).
F. Mood stabilizers, lithium (low dose, e.g., $300 \mathrm{mg} \mathrm{SA}$ at bedtime).
G. Mood stabilizers, anticonvulsants (valproate, carbamazepine, oxcarbazepine, topiramate, and lamotragine).
H. Atypical antipsychotics (aripiprazole, olanzapine, ziprazadone, and quietapine).
I. Nonbenzodiazepine anxiolytics.

VI. Sexual Health and Libido.

A. Treatment for hypopituitarism.

B. Avoid medications that decrease libido (note adverse effect of SSRIs).

Figure 3.

Summary of treatment considerations for neurobehavioral disorders (avoid narcotics, benzodiazepines). SA = sustained action, SNRI = serotoninnorepinephrine reuptake inhibitor, SSRI = selective serotonergic reuptake inhibitor.

involving the dorsolateral prefrontal cortex and basal ganglia and operates a "visual spatial sketch pad" (images) and a "phonological loop" (acoustic). Long-term storage (also referred to as short-term [sic] or long-term memory and episodic memory) maintains perceived information in a solidified form for a time period but is subject to decay parameters based on the nature and strength of the saved trace. This solidification of declarative or episodic information details occurs as a consolidation of neuronal firingpattern traces in the association cortex regions, which are posterior to the central sulcus (in the parietal and temporal lobes), in the same distributed neural networks responsible for perceiving information [40-41]. The operations that induce solidification of a perception involve reciprocal connections with two specific medial temporal lobe structures, the hippocampus (autobiographic, location, episodic memory, etc.) and the amygdala (emotional conditioning, information evaluation on its importance to the individual) [40], and systems associated with the medial temporal lobe, including the Papez circuit (hippocampus, fornix, mammillary bodies, and cingulum) and the Nauta circuit (basolateral limbic circuit that includes the amygdala, dorsomedial nucleus of the thalamus, and the frontal lobes) [42-44]. Learning and memory are also influenced by 
neurons with thin, unmyelinated, corticopedal fibers projecting from cell bodies in the brain stem, including the acetylcholine neurons of the nucleus basalis of Meynert (detail learning), the norepinephrine neurons of the locus coeruleus (reward-related learning/Skinnerian conditioning), and the serotonin neurons of the dorsal raphe nucleus (classical/ Pavlovian conditioning).

A central issue concerning memory is relearning lost skills and abilities, a critical part of rehabilitation. Fundamental neuroplastic mechanisms exist in the brain to form new connections, and many neuroplastic processes are activated to recover from brain injury. Some of these processes are facilitated by dietary and hormonal factors. However, some aspects of these processes require higher levels of learning to activate the formation of the needed new pathways. If fundamental memory mechanisms are not working, then recovery will be more difficult. Potentially, the neuroplastic processes may be augmented with medications and complex stimulation.

Criteria and Assessment. Memory dysfunction following TBI may be acute or chronic. Acute dysfunction is described in terms of PTA and PCS, as just described, and is generally time-limited. Sim et al., for example, found that postconcussive athletes' reaction times and processing speeds returned to normal within 6 days, and memory impairment usually resolved without intervention within 10 days postconcussion [45]. However, such recovery will depend on the severity of damage to the affected systems in a particular individual.

Chronic memory impairment following TBI has not been labeled diagnostically. Chronic memory storage impairment may persist for years and involve deficits in medial temporal lobe processing (particularly hippocampal and/or amygdaloid) as shown by difficulty encoding or retrieving recent memory. Specific memory deficits can be related to the damage of related cortical regions.

Acute memory disturbances such as PTA may be assessed with use of the guidelines the AAN described or with similar grading systems. The Standardized Assessment of Concussion includes measures of cognition, including orientation, immediate recall, concentration, and delayed recall (after few minutes and a distraction). Chronic disorders of memory may be assessed at the bedside and usually involve administration of simple cognitive tests that measure various aspects of working memory and storage ability. This level of testing is useful for screening. One of the most common assessments involves asking the patient to repeat a list of three items (immediate recall) and repeat them again at the end of testing (delayed recall) [46]. For individuals with evidence of memory dysfunction, a formal neuropsychological assessment is more detailed and may include learning a variety of materials, such as stories, lists of words, or pictures [46-49].

Treatment Options. Treatment during the primary phase of recovery from a TBI, which is due to direct physical insult and may involve damage to neuronal cell bodies and their arborizations, is difficult because of the short window of opportunity [50]. Treatment for secondary or delayed injury, which results from a complex cascade of molecular, cellular, and biochemical events lasting days to several months, is more promising [51]. Pharmacological targets include neurotransmitter pathways, excitatory amino acids (modulators), calcium channels (blockers), reactive oxygen species (scavengers), inflammation (anti-inflammatory agents), caspases, calpain (inhibitors), endocrine metabolism (treatments), and neurotrophic factors. Various agents targeting biochemical and cellular events are in various phases of clinical trials [50]. Treatment for long-term sequelae can be targeted with respect to treatments for the conditions that are comparable with those seen in other clinical settings.

Cholinesterase inhibitors, for augmenting neurotransmitter function in acetylcholine systems, are Food and Drug Administration (FDA)-approved for treating dementia related to $\mathrm{AD}$ and have been used increasingly off-label for a variety of cognitive deficits. Although no drug used for treating dementia currently has FDA approval for also treating TBI, several such compounds have been examined in clinical studies. For example, donepezil has shown some efficacy in the treatment of TBI-related memory problems [52-55] and rivastigmine has been shown to be safe and well tolerated in a prospective, randomized, double-blind, placebo-controlled study of 157 patients with TBI with moderate to severe memory impairments [56]. Galantamine has been beneficial in treating memory loss in long-term trials [57].

Other medications have been tried in treating memory losses in patients with TBI. For example, memantine, an $\mathrm{N}$-methyl-D-aspartate (NMDA) receptor modulator, which may protect against glutamatergic excitotoxicity and is FDA-approved for treating moderate to severe dementia associated with $\mathrm{AD}$, has been shown to prevent neuronal loss in rodent TBI models, specifically in the hippocampus [58], and has shown promise in a pilot trial for treating PTSD [59]. Methylphenidate, a catecholaminergic stimulant, has been examined, with studies suggesting varying degrees of efficacy [60-61]. No large-scale trials of these 
medications exist, and little is known about the moderators or mediators of treatment response.

Neurogenesis occurs in neural stem cells of the subventricular zone of the lateral ventricles, subgranular layer of the dentate gyrus, and olfactory bulbs. Neural stem cells express acetylcholine receptors, and animal studies have shown that treatment with acetylcholinesterase inhibitors promote survival of these newborn neurons under both normal and stressed conditions [62]. Selective serotonergic reuptake inhibitors (SSRIs) [63] and lithium [64-65] may also increase adult hippocampal neurogenesis and reverse stress-induced cognitive damage. Bremner and Vermetten demonstrated that patients with PTSD treated for 1 year with an SSRI increased their hippo-campal volume 5 percent and improved their verbal declarative memory function 35 percent [63]. These treatment modalities that promote neurogenesis need to be more fully explored in treatment of TBIrelated cognitive deficits.

\section{Attention}

Definition and Neurobiological Basis. Impairment of attention focus is common following TBI and is seen across the TBI severity spectrum [66]. Attention can be understood as "a control process that enables an individual to select, from a number of alternatives, the task to be performed, or the stimulus to be processed, and the cognitive strategy to be adopted to carry out the operation" [67]. "Attention is a multidimensional construct composed of such phenomenon as strategic scanning, exclusion of irrelevant stimuli, sustained attention, divided attention, inhibition of impulsive action, and selection and monitoring of response" [68]. Van Zomeren and Brouwer initially proposed fundamental components of attention: "focused," "divided," and "supervisory” [69].

Margulies proposed that the hippocampus mediates selective attention, in which sensory data are conveyed to the hippocampus and matched against a cognitive "map," so as to determine whether or not a stimulus should be noteworthy, determination-based novelty, emotional valance, and salience [70]. Hippocampal selective attention may also be modulated phasically by norepinephrine, diurnally by serotonin, and over the long term by corticosteroids [68]. This theory is contrasted with the noradrenergic theory of attention deficit disorder [71-72], which suggests that attention deficit and hyperactivity are due to an increase in noradrenergic transmission from the locus coeruleus. A tonically high noradrenergic state may reduce the threshold of the hippocampus to stimuli, thus leading to increased distractibility, a "merger" of the two theories [68]. Of note, the hippocampus is reciprocally connected to posterior cortical regions, which also receive norepinephrine input, and processing is likely done in a mass, hierarchical, parallel-distributed processing fashion, as formulated by Ashford et al. and others [40-41,73-74].

Attention is generated by multifaceted neural processing that coordinates broad cortical integrative systems for specific processing requirements [75], rather than locally restricted analyses [76-77]. A variety of specific neural networks responsible for attention are widely distributed across various cortical regions with important nodes in the brain stem; frontal, temporal, and parietal regions; and cingulate cortex [75,77]. The parietal or spatial attention networks interact with limbic and monoaminergic systems to modulate motivation-induced attention shifts [77]. Thus, attention coordination recruits large arrays of neural populations, rather than restricting processing to a limited distribution.

Disruption of any of the brain structures associated with coordinating cerebral processing can disrupt critical aspects of attention. Furthermore, a pathophysiological relationship could exist between TBI and ADHD. Although TBI symptoms can mimic those of ADHD, by the DSM-IV definition, ADHD cannot be diagnosed in the presence of TBI. ADHD is primarily recognized as a childhood or developmental condition. ADHD was formerly described as minimal brain injury syndrome or minimal brain dysfunction [78] that displays inattention, impulsivity, and hyperactivity. Although ADHD cannot be diagnosed in the presence of head injury, one may diagnose MNI to capture the symptoms of inattention and use this relationship for evaluation and treatment development.

Criteria and Assessment. Patients with TBI typically present with complaints of concentration difficulties, distractibility, difficulty multitasking, and decreased processing speed. The patients may be impulsive and hyperactive. Patients may not be able to verbalize "I can’t focus," so symptoms of inattention should be sought when a patient presents with many days of missed work or frequent job changes.

A typical bedside assessment of attention involves asking a patient to name as many animals as possible in $1 \mathrm{~min}$, repeat a series of digits forward and backward, perform "serial sevens," or spell a common five-letter word backward. The Conners Scale is an instrument that uses observer ratings and self-report ratings to help a clinician assess ADHD and evaluate problem behavior in children and adolescents. This scale has been modified 
for assessing adults [79] and may help clinicians assess the severity of ADHD symptoms and their response to treatment. For moderate to severe TBI, the Moss Attention Rating Scale has been used during acute inpatient rehabilitation and exhibits good interrater reliability [80].

Based on the fundamental components of attentionfocused, divided, and supervisory [69]—neuropsychological instruments can be directed to each component of attention including-

1. "Focused Attention": Stroop Color and Word Test [81], TR Distraction Task [69].

2. "Divided Attention” test: Trail Making Test, parts A and B [82], RT Dual Task [83-84], Paced Auditory Serial Addition Task or PASAT (modified from Gronwall and Sampson [85-88]).

3. "Supervisory Attention": Relative Preservation Error Score or PERSREL (derived from the Modified Card Sorting Test) [89], Lack of Consistency Score derived from the 15 Words Test [90].

Spikman et al. examined the construct validity of these three aspects of attention in nondisabled individuals and patients with TBI [91]. The results demonstrated no difference in scores for focused attention and divided attention. However, a difference was found in the supervisory attention category. The authors noted focused, divided, and supervisory constructs are not separate entities and exist in a phenomenological context only. Individuals with TBI approach problem-solving tasks in a quantitatively different way because of a shift in response control. In response-control shift, patients may exert a greater or lesser amount of executive control than they would have done before their TBI, a speed-accuracy trade-off: emphasizing speed with increased risk of errors versus emphasizing accuracy and subsequently reducing speed of task performance. Slowing of information processing following TBI has also been extensively demonstrated [83-84,92-93]. Clinicians should consider these elements when assessing an individual's attention performance: control and speed (also demonstrated in other studies; see Spikman et al. [91] along with task structure). Several studies have led to the conclusion that executive control should be viewed as a core component of performance in attention tasks. Zoccolotti et al. [94] examined selective (focused, divided) attention and intensive (alertness, vigilance) attention processing in 106 patients at 5 months post-TBI. Widespread deficits affecting selective and intensive attention processes were not observed. Factor analysis identified two main subgroups. Patients in the first subgroup, characterized by more severe TBI as evidenced by a lengthier coma, were more impaired in selective and divided attention. In the second patient subgroup, alertness was indistinguishable from control, but a decrease in divided attention abilities was observed, in contrast to the findings from Spikman et al. [95], who attributed attention deficits to a general slowness factor. In a third small subgroup, individuals reacted slowly to visual stimuli and were unable to perform divided attention tasks.

In the Divided Attention test, a subject is required to divide his attention between two tasks simultaneously: one acoustic, one visual [94]. An inability to acquire information simultaneously from both sensory channels results in an omission of target response and/or slowed response. Patients ranked tasks of the Divided Attention test to be the most difficult. The literature emphasizes the importance of divided attention tasks because of their relevance to everyday functioning [69]. The inability to divide attention into different channels may hinder a patient's ability to effectively return to study or work [96].

Treatment Options. As in the case of memory deficits, no large-scale studies of treatments for attention deficits exist in TBI, and consequently, no treatments are specifically or definitively recommended. However, the need for management of attention problems has led clinicians to consider attention deficit treatment models in other populations, such as children with ADHD. For example, the Texas Medication Algorithm Project-guided treatment provides a useful treatment guideline for examination because several medications used to treat ADHD have been used to treat similar symptoms in TBI [4]. The Texas Medication Algorithm Project delineates a multistage approach, outlined as follows:

1. Stimulants are the drug of first choice in the treatment of ADHD [97-101], because an extensive body of evidence indicates that 75 percent of those with ADHD are responders. The effect size of this class of medication reaches 1.0, one of the largest effect sizes of any psychotropic medication [102]. By analogy with TBI, the stimulant methylphenidate has been studied and suggested to be helpful in TBI-related inattention [61,66,103-104]. Though less well studied, the stimulant dextroamphetamine has shown similar effects in TBI-related inattention [105-106].

2. For second-line treatment of ADHD, atomoxetine is a specific noradrenergic reuptake inhibitor with an effect size of 0.7. However, little evidence exists yet for the use of this medication in treating TBI-related inattention [107]. 
3. Bupropion has been well established as an off-label agent in ADHD treatment, but has not been studied in TBI-related ADHD-like symptoms.

4. The alpha-2 agonists are frequently used as adjunctive treatment in ADHD but specifically for the impulsive and hyperactive components. Individuals treated with clonidine following TBI demonstrated a reduction of plasma norepinephrine and a normalization of plasma epinephrine. The reduction of sympathetic overactivity is probably due to the specific action of clonidine on alpha-2 adrenoceptors within the rostral ventrolateral medulla [108].

The Texas Medication Algorithm Project also provides additional treatment options of ADHD-associated comorbidities such as depression, anxiety, and aggression. Modafinil, a currently available stimulant medication, while not incorporated into the Texas Medication Algorithm Project, has improved significantly in both inattentive and combined types of ADHD in three double-blind placebo-controlled studies [109]. The effect of modafinil in treating TBI-related ADHD-like symptoms has not been demonstrated.

Additional options for treating attention problems may also be considered. Acetylcholinesterase inhibitors, such as donepezil, have helped increase short-term memory scores and attention in psychological testing during a 24-week randomized, placebo-controlled, double-blind crossover study [54]. Long-term use of donepezil may prove deleterious because of the induction of cholinesterase overactivity, although galantamine (now available in a generic formulation) may not have this adverse consequence. Memantine, an NMDA receptor modulator, has been investigated by Findling et al. in a pilot open-label 8-week evaluation of pediatric ADHD using 10 to $20 \mathrm{mg}$ doses a day [110]. Dosages were well tolerated and were found to be effective in improving inattention; results appeared to be dose-related. Effects of memantine on TBI-related inattention have not been examined. Noncompetitive NMDA receptor antagonists, such as amantadine, have received little attention as agents in treating TBI-related cognitive dysfunction. Two case reports; three retrospective studies; and two randomized, double-blind, controlled trials of amantadine therapy have been reported and indicate that this medication may be a promising therapy [111-112]. One study of a dopamine receptor agonist, bromocriptine, showed that it did not benefit individuals presenting with inattention following moderate to severe TBI, even possibly being associated with adverse events [113].

\section{Communication: Linguistics-Speech and Language}

Definition and Neurobiological Basis. TBI causes a range of communication deficits that cannot be explained in classical terms of aphasia [114-116]. Rather, these deficits are best described as cognitive-communication disorders or cognitive pragmatics [117]. Language and thought are closely related in brain organization and social function. Language facilitates certain types of complex thought and cognition by allowing subvocalization and organization of thoughts for performing more complex mental operations. Damage to the language centers, therefore, not only impairs the ability to communicate but also interferes with the ability to organize complex cognitive processing.

The basis of communication is information exchange between two participants who attempt to achieve several objectives, beginning with understanding the mind-set of the interlocutor. For example, in the act of being deceitful, what an actor intentionally communicates conflicts with the actor's private mental state, but that communicated information does not contrast with the knowledge that is disclosed to the partner. In case of deceit comprehension, the partner recognizes the difference between what is expressed and the ideation the actor privately entertains. In addition, in irony, that which an actor intentionally communicates also contrasts with the knowledge he/she shares with the partner. This complex mixture of information makes an ironic communication act more difficult for a listener to recognize and understand than a deceitful one. Linguistic (syntax, lexical), extralinguistic (gesturing), and paralinguistic (tone, intonation, rhythm, and prosody) elements of communication are then set in motion. During a communicative exchange, individuals will match their linguistic and extralinguistic acts with appropriate paralinguistic aspects. Communication is also governed by cooperative principals and rules of politeness (e.g., when, how, and what a person is allowed to say about social status, hierarchical position, or level of formality) [118].

In TBI, the location and extent of the injury determine the type and the degree of language and speech impairment. Damage to certain regions of the language centers of the dominant hemisphere (for most individuals, the left hemisphere) produces aphasia. Aphasia can be differentiated clinically into two broad categories: "impaired repetition" (Broca, Wernicke, global, and conductive aphasias) and "preserved repetition or isolated aphasia” (motor, sensory, mixed, and anomic aphasias) [119]. One can characterize these aphasias according to the variation of the deficits in naming (object identification), fluency (smoothness or flow with which sounds, 
syllables, words, and phrases are joined when speaking), comprehension (verbal understanding), and repetition (ability to repeat a phrase) [120]. Impaired repetition may be related to damage to Wernicke's area for language reception, producing a receptive aphasia; to Broca's area for language expression, producing an expressive aphasia; or to the arcuate fasciculus (a bundle of the superior longitudinal fasciculus), which connects Wernicke's and Broca's areas, producing a conduction aphasia [119].

TBI-induced damage to the language centers may impair social functioning as well. Although the dominant hemisphere is responsible for vocabulary and syntax, concepts may originate in either hemisphere or may be a function of cross-hemispheric interactions. Pragmatic language is located in the nondominant hemisphere and is disrupted by frontolimbic damage [121]. Damage to this center may impair the patient's ability to comprehend jokes, irony, or even speaker intention. Furthermore, social language functioning may be compromised by dominant hemisphere injury, such as the capacity to organize discourse. In addition, such damage may disturb speech prosody, and these individuals may speak with disordered intonation, rhythm, or inflection.

Criteria and Assessment. Milton et al. suggested that inappropriate communication following TBI is the most severe obstacle for patients to surmount when socially reintegrating [122]. Communication difficulties impair social interacting, and changes in sociability may be the most destabilizing of sequelae following TBI and certainly the most invalidating [123-126]. These disorders are significant factors in poor psychosocial adaptation following injury [127-129]. Individuals with TBI have difficulty processing language efficiently [130], manifested as inappropriate topic-switching and turn-taking, poor conciseness [131], self-focused conversation, inappropriate humor, inappropriate levels of self-disclosure [132], and wordfinding difficulties [133]. Several studies have shown that individuals with TBI demonstrate impaired paralinguistic processing that may be due in part to an impairment in recognizing emotions expressed by others, both in their voice and their facial expression $[121,134]$. This latter deficit may be the causal factor for antisocial behavior and poor social relationships following TBI.

Speech evaluation assesses the patient's abilities in object-naming, fluency, comprehension, and repetition. Language can be measured at the bedside by listening to the patient speak and using simple requests, including identifying objects and repeating various words and phrases (e.g., "no ifs, ands, or buts"). Collateral history may be elicited by asking family members if their loved ones are able to read social cues, enjoy jokes, or understand irony. Observation of specific language difficulties or reports of nonspecific interaction problems should lead one to consider formal testing.

One formal language test is the Assessment Battery of Communication, which may help in evaluating pragmatic language disorders in individuals with TBI [118]. This assessment battery is made up of five different evaluation scales, such as linguistic (syntax, lexical), extralinguistic (gesturing), paralinguistic (tone, intonation, rhythm, and prosody), context, and conversation, that investigate all the principal aspects involved in communicative exchange.

Treatment Options. Currently, the main treatment for aphasia is conventional speech and language therapy that depends on the brain's ability to recover function through neuroplastic processes (learning and memory), which may be activated and enhanced by exercise and medications. Empirical observation suggests that spontaneous biological recovery may also partly explain the improvement in language function [135].

Pharmacotherapy adjuncts to speech and language therapy have been used and include monoaminergic (bromocriptine, levodopa, d-amphetamine) and cholinergic (donepezil, rivastigmine, galantamine) agents [136]. The efficacy of these treatments has not been determined; however, limited results using piracetam and amphetamine have been demonstrated [137]. Dextroamphetamines improve attention span and enhance learning and memory, which are essential for acquiring new motor and cognitive skills, thus leading to a more rapid recovery from aphasia. Minimal investigation of these agents has been conducted in TBIrelated aphasia, and overall, the literature is sparse regarding pharmacological treatments of pragmatic language disorders. Specialized computer and Internet training materials have been increasingly used and shown to benefit individuals with TBI suffering from cognitive-linguistic impairments [138]. Some studies have indicated that repetitive transcortical magnetic stimulation may be an effective adjunct to speech and language therapy [139], but recommendation of this therapy awaits replication of the initial studies and further demonstration in careful studies of specific language disorders.

\section{Communication: Affect Recognition and Emotion Expression}

Definition and Neurobiological Basis. Affect recognition has been a study of science for decades but has 
only been addressed recently concerning TBI. Consequently, little data are available concerning the incidence and prevalence of disorders of affect recognition in TBI. However, inappropriate expression of emotion and loss of inhibitory control of affect, i.e., lability, are common in patients with TBI.

Generally, functional impairments following TBI may be seen in all aspects of daily functioning, including reduced employment and impaired social relationships with subsequent reduction in QOL [3]. Psychosocial impairment is typically seen within the realm of interpersonal communication [140], which involves the perception of emotion, empathy, recognition of faux pas, and behavior. Several studies have shown that individuals with TBI have significant difficulties recognizing nonverbal cues of affect [141-152], resulting in inappropriate behavior [153], thereby affecting social relationships [154]. Emotion recognition is pivotal in engaging social interaction [155-159] and developing and maintaining support networks.

Poor outcomes following TBI are associated with inadequate social support networks, which are poorly maintained when interpersonal skills deteriorate [160]. LoBello et al. found that not only those with TBI but also their families experience a shrinking of social networks [161] and that one-third of families at follow-up have problematic interactions [162]. Caretakers of individuals with diminished social support experience higher levels of stress [163-164]. Marriages are also found to be more likely to end in divorce or separation due to loneliness, altered interpersonal skills [165], and unpredictable behavioral patterns [166]. Problems with affect recognition are also seen in individuals with autism spectrum disorder [159,167-169], which may be heuristically related to some varieties of TBI sequelae.

Recognition and response to facial affect in others and an individual's facial affect expression are related to processing in the prefrontal, parietal, and temporal cortices and the limbic system. The prefrontal cortex, particularly the ventral medial aspect, allows one to experience one's own emotions, and the absence of which impairs one's ability to recognize emotion in another $[150,170]$. The orbital frontal cortex is responsible for the intensity of emotional expression [171].

In conditions such as autism in which recognition of affect is problematic, research has shown that the temporal lobe and amygdala may analyze facial affect one feature at a time [156,172-173]. In contrast, the fusiform area of the temporal lobe, in normal function, processes facial features as a whole, a "gestalt," and in parallel [174-175]. The amygdala is pivotal in facial affect recognition, especially fear [176-179], damage to which may cause an individual's innate fear response to change with subsequent difficulty in recognizing fear in others. Adolphs et al. found that individuals with such damage were unable to recognize emotion from faces in pictures where only the eyes were visible [173]. These individuals spend more time looking at the nose and mouth regions than controls.

Criteria and Assessment. No specific post-TBI emotional, affective, or "para-autistic" syndromal criteria or assessment scales have been developed at this time. The DSM-IV-TR criteria for autism may help assess these "para-autistic" features that develop following TBI. The two criteria are qualitative impairments in (1) social interaction and (2) communication. The first criterion, impaired social interaction, may be manifested as marked impairment in the use of multiple nonverbal behaviors such as eye gaze, facial expression, body posture, and gestures to regulate social interaction; a failure to develop peer relationships; a lack of spontaneous seeking to share enjoyment, interests, or achievements (e.g., by lack of showing, bringing, or pointing out objects of interests); and a lack of social or emotional reciprocity. The second criterion, impaired communication, may be manifested by marked impairment in the ability to initiate or sustain conversation.

Many families report that following TBI, the veteran is "not the same" or is just "a shell of the prior self." The clinician needs to carefully observe the communicative transaction between patient and family members as well as the exchange with the clinician. History-taking may be enriched with these "para-autistic" impairments in mind.

Without specific criteria, the clinician may appropriately use any of the several dozen autistic rating scales available. The Diagnostic Interview for Social and Communication Disorders, used to assess children and adults of any age, is an interviewer-based schedule for use with parents and caregivers. It primarily helps the clinician obtain a developmental history and description of the child or adult concerned. It also helps the clinician to understand a pattern of skills and impairments that underlie certain behaviors [180].

Treatment Options. Cognitive strategies such as those used to treat autism may help treat communication and affect issues related to TBI. Such strategies may include teaching patients to attend to relevant facial features, such as eyes and their openness, and to be able to associate 
certain facial features, such as wide open eyes, with fear. Clinicians may use static pictures initially followed by videos demonstrating faces that vary in emotion and intensity. Negative facial features should be used more, because they are more difficult to interpret. Role playing and practicing facial expression in a mirror for feedback may benefit patients as well. They should be encouraged to become more aware of their own emotional experiences and how their new limitations (e.g., difficulty reading people) affect their social and occupational functionings. Family instruction will help eliminate the idea that their loved one "just doesn’t want to" but instead is "unable to" [160].

\section{Visuospatial Perception and Sensory-Motor Integration}

Definition and Neurobiological Basis. The incidence and prevalence of apraxia and agnosia in mild or moderate TBI are unknown. However, deficits of the parietal and temporal lobes are associated with agnosia and apraxia. Agnosia is difficulty identifying or recognizing various sensory stimuli: astereognosis (impaired tactile recognition) due to lesions of the contralateral parietal lobes, and visual agnosia (impaired visual recognition) due to parieto-occipital lesions. Apraxia is the inability to carry out a motor act despite intact motor and sensory pathways. Ideomotor apraxia is the inability to perform motor responses on verbal command (for example, a patient cannot pinch his nose when asked but is able to do so spontaneously). A variety of brain structures are implicated in ideomotor apraxia, including the corpus callosum, the arcuate fasciculus, and Broca's area. Ideational apraxia is inability to conceptualize movements, and patients with this disability have difficulty sequencing different components of a complex task, although each separate component can be performed separately. Ideational apraxia is seen following lesions of the left parieto-temporo-occipital area and frontal lobes. Constructional apraxia is the inability to draw or construct two- or three-dimensional figures or shapes [120,181].

The action of picking up a tool and using it requires a complex hierarchy of parallel processing [41,74], which can be described as a "ready, set, go" mechanism. "Ready" entails, for example, "deciding to pick up a tool for use." This decision may occur in the dorsolateral prefrontal cortex. "Set" determines the identity of the tool based on intrinsic properties such as shape, size, and color, which are analyzed along the ventral visual pathway that projects from the occipital cortex to the temporal lobe. Next, the object needs to be located because of its position in space, which depends on the dorsal visual pathway, which projects from the occipital cortex to the parietal lobe. Then, the status of the information of the shape, color, size, and location of the object in space is provided to the premotor areas to plan the execution of the task. The set of muscles to be used is determined, and then their sequence, force, amplitude, and speed of contraction are planned by the premotor areas. This information is sent to the "go" center, the primary somatomotor cortex, which executes this motor plan by way of the motor neurons projecting to the spinal cord. The movement trajectory is modulated by neural loops involving the cerebellum and the basal ganglia. Any of the neural fiber pathways subserving these systems and functions may be disrupted by TBI and lead to consequent dysfunction.

Criteria and Assessment. Apraxia and agnosia are well documented in individuals with stroke and severe TBI, and symptoms are usually overt and relatively easy to detect. In mild TBI, deficits may be more subtle, so syndromal criteria are needed. In review of these conditions, asking the patient if she or he has any difficulty writing, holding a pen, buttoning clothes, or "being clumsy" can be useful. Relatives may complain that the patient is able to wash a cup by him- or herself but is too "stubborn" to do so when asked, which may indicate an ideomotor apraxia. In the assessment of agnosia, patients may not be able to convey their difficulty finding words or remembering the names of objects, so capacity should be determined with specific questions.

A clinician can identify disorders of perception and integration in the neurological examination by requesting an individual to identify simple objects such as a key by sight using the visual system (apperceptive, associative) or by touch using the somatosensory system (astereoagnosia). Once motor and sensory pathways are deemed intact, the patient may be asked to pick up a pen. If the patient is unable to perform this task despite collateral confirmation to the contrary, then ideomotor apraxia may be considered. In the assessment of apraxia, a three-step command such as "point to the door, point the ceiling, and then raise your right foot" may be given. If the patient is unable to perform the three-step command in its entirety but is able to complete the task when commands are given as individual steps, ideation apraxia may be considered. An inability to copy geometric figures, such as a cube, may indicate a constructional apraxia.

Assessment of perception and integration is part of formal neuropsychological testing for TBI. Block design 
test (Kohs, 1923 [182]) is a test of parietal function and requires the patient to take blocks that have all white sides, all red sides, and red and white sides and arrange them according to a pattern. Temporal lobe function is assessed by tests that require a patient to identify a sequence of pictures, such as the Boston Naming Test [183].

Treatment Options. For patients with apraxia, cognitive-physical rehabilitation is the treatment modality of choice [184], including such interventions as behavioral training programs consisting of gesture-production exercises [185]. Medications that may promote neurogenesis, such as SSRIs [63], lithium [64-65], and cholinesterase inhibitors [62], may potentially be used as adjuncts in cognitive rehabilitation, although these agents have not been investigated adequately in the population with TBI [4].

\section{Executive Function}

Definition and Neurobiological Basis. The frontal lobes are especially vulnerable to injury following a TBI [186], resulting in a variety of cognitive and behavioral changes that significantly affect functional outcome [187]. Although all cognitive functions are phenomena of distributed neural processing networks that do not possess a singular location [40], executive processing occurs largely within the prefrontal cortex, in collaboration with other cortical regions and systems [41]. Important prefrontal sites of coordination or executive control include the anterior cingulate gyrus, orbital frontal gyrus, and dorsolateral prefrontal cortex [188]. The prefrontal cortex, in addition to being modulated by projections from acetylcholine, serotonin, and norepinephrine neurons, is unique among neocortical regions, in that it also receives projections from dopamine neurons. The prefrontal cortex works along with the basal ganglia, in particular the nucleus accumbens, which also receives projections from serotonin, norepinephrine, and dopamine neurons and has cholinergic and gamma-aminobutyric-ergic interneurons. Consequently, agents that affect any of these systems can influence the function of the prefrontal cortex.

Based on clinical experience with ADHD, Brown conceptualizes executive function within six clusters of cognitive functions: (1) activation: organizing, prioritizing, and activating to work; (2) focus: focusing, sustaining focus, and shifting attention to tasks; (3) effort: regulating alertness, sustaining effort, and processing speed; (4) emotion: managing frustration and regulating emotions; (5) memory: utilizing working memory and accessing recall; and (6) action: monitoring and regulat- ing self-action [189]. Thus, executive function is an integration of selected cognitive resources, which allows an individual to perform daily tasks (e.g., paying bills, making and keeping appointments, shopping, cooking).

Criteria and Assessment. TBI of the frontal lobes with subsequent impairment of executive function [190] may be associated with poor vocational functioning and community integration [191-192] and with apathy and disinhibition. Simple tests for executive function include asking a patient to name as many animals as they can in a minute as well as similarities (How are a banana and orange alike?), differences (How are a lie and a mistake different?), and abstraction (proverb interpretation). However, inquiring about interests and the appropriateness of social behavior is also important.

Large studies utilizing the National Institute on Disability and Rehabilitation Research TBI Model Systems database have failed to demonstrate impaired executive function at 1 year postinjury [193]. One possible explanation is that traditional neuropsychological testing measures are less sensitive to behavioral changes such as apathy and disinhibition [194-196], although the great heterogeneity of TBI presentation makes a single dysfunction difficult to find among the extraordinarily complex array of possible problems that could occur. Rather, the important focus is on the individual patient, defining that patient's difficulties and trying to help that patient cope with those difficulties.

The Behavior Rating Inventory of Executive Function (for ages 0-18) [197] and the Frontal Systems Behavior Scale (for ages 18-95) [198] have good reliability and validity in distinguishing individuals with frontal lobe injury from those with other lesions [199]. The Frontal Systems Behavior Scale assesses apathy (anterior cingulate gyrus), disinhibition (orbital frontal), and executive function (dorsolateral prefrontal cortex) [188] and effectively detects such changes in individuals with mild cognitive impairment, AD [200], or polysubstance abuse [201]. Importantly, returning veterans may not be fully aware (metacognition) of their deficits [202].

Metacognition is an important aspect of mental function and is the capacity to "think about thinking," the mind's creation of mental representations about itself. Metacognition involves the idea of appearance-reality distinction, i.e., things are not always the way they appear. One facet of metacognition is representational diversity: essentially what one person thinks about an event may be different from another. In addition, what 
one thinks today about an event may be different from what one thinks the following day (representational change) $[68,203]$. Patients with TBI score poorly on the self-awareness questionnaires, and decreased metacognitive self-awareness is correlated with increased problems in some components of the executive system, even when the self-awareness questionnaire subscales are considered separately [204]. The literature has inconsistencies regarding the concept of awareness. A comprehensive model of awareness is needed to guide the development of measurement tools and interventions (for more information, see Toglia and Kirk [205]).

Treatment Options. A few drug trials have examined changes in executive function in patients with TBI. Bromocriptine, a dopamine enhancer, improved prefrontal functioning in such measures as initiation and mental flexibility in one double-blind, placebo-controlled, crossover study [206]. Treatment of individual cognitive domains, such as attention or memory, may improve overall executive function. Given the close interaction between studies of executive function and ADHD [189], treatment of problems in executive function may be best related to the treatments developed for ADHD (see the "Attention" section under “Treatment Options” for attention problems).

\section{Neurobehavioral Disorders}

The epidemiology and risk factors for noncognitive psychiatric disorders associated with TBI (depression, mania, PTSD, psychosis, agitation, and aggression) have recently been reviewed [21]. A significant additional neurobehavioral concern is sexual health and the impairment of libido. Numerous neurobehavioral syndromes are associated with TBI, although the evidence of specific associations in rigorous studies is lacking. Again, with the diversity of TBI, the neurobiological bases of TBI contributions to behavior problems are complex. However, clinical experience recommends practical management of these problems. These suggestions are outlined in Figure 3.

\section{Mood}

Definition and Neurobiological Basis. Depression is defined in DSM-IV-TR and is a fundamental problem addressed in the field of psychiatry. The incidence of postTBI depression ranges from 15.3 to 33.0 percent [207208], while the prevalence ranges from 18.5 to 61.0 percent $[21,209-216]$. These large ranges are likely due to the overlap of depression and postconcussive type symptoms (e.g., poor concentration, irritability, fatigue, sleep disturbances).
The clinician must elucidate whether these symptoms are due to the emergence of a major depressive disorder or are related to PCS or apathy.

Suicide is a severe and devastating outcome of many psychiatric illnesses, particularly depression. In 2004, 32,439 Americans committed suicide, the equivalent to 89 suicides a day (11 per 100,000). In the general population, suicide is the twelfth leading cause of death, while it is the third leading cause of death in those aged 20 to 24, the second leading cause of death in those 25 to 34 , and the fourth in those 35 to 44, ranging from 3.5 times higher in males than females aged 20 to 24 to 1.9 times higher in those aged 45 to 54 (Table) [217]. Approximately 52 percent of U.S. military personnel are aged 20 to 30 . A TBI is likely to put individuals at even greater risk for suicide, because individuals with TBI have a three- to fourfold increase in successful suicides, an increase in suicide attempts (18\%), and an increase in suicidal ideation (21\%-22\%) [218]. In 2004, the U.S. Army began using the Army Suicide Event Report, a 12-page standardized Web-based report to collect data on suicide-related events. According to this reporting system, an increasing trend exists in suicides: 67 suicides in 2004 (10.8 per 100,000), 87 in 2005 (12.8 per 100,000), and 99 in 2006 (17.3 per 100,000), although these numbers need to be considered relative to age and sex with respect to the numbers for the general population, which are actually higher. As of June 2007, 44 suicides occurred among active duty personnel (including reserve and National Guard), 17 of which were completed during Operation Iraqi Freedom and Operation Enduring Freedom (OIF/OEF) deployments in Iraq and Afghanistan. Of the suicides, 89 percent were male, 64 percent were Caucasian, 49 percent were under the age of 25, 91 percent were in the regular Army division, 49 percent were never married, and 36 percent were married. In contrast to the

Table.

U.S. 2004 mortality statistics for suicide, rate per 100,000, by age range. Note that suicide rate is two to four times higher for male than female Operation Iraqi Freedom and Operation Enduring Freedom veterans, with slightly higher rate for those $>35$ than for those $<35$ years of age.

\begin{tabular}{ccccc}
\hline Age Range & Male & Female & Total & $\begin{array}{c}\text { Male/ } \\
\text { Female }\end{array}$ \\
\hline 20-24 & 20.8 & 3.6 & 12.5 & 3.5 \\
$25-34$ & 20.4 & 4.7 & 12.7 & 2.7 \\
35-44 & 23.0 & 7.1 & 15.0 & 2.1 \\
45-54 & 24.8 & 8.6 & 16.6 & 1.9 \\
All Ages & 17.7 & 4.6 & 11.0 & 2.4 \\
\hline \hline
\end{tabular}


Army data, in the Marine Corps - a smaller force-24 suicides were recorded in 2006 (12.4 per 100,000), with 4 suicides occurring in a war zone. The reliability of these data is unclear and may underestimate suicides because suicides may have been misclassified as accidents, "undetermined," or "pending determination status" [219]. The magnitude of suicide misclassification in a nonmilitary environment is considerable, with 20 to 30 percent of suicides being inaccurately assigned [220-223].

The neurobiology of depression remains unclear, but some relationship certainly exists between serotonin and norepinephrine systems, since medications that affect these systems benefit patients with depression. Serotonergic neurons (whose cell bodies are located in the raphe nucleus of the brain stem) and norepinephrine neurons (whose cell bodies are in the locus coeruleus nearby) have unmyelinated axons that measure several centimeters long and project throughout the brain and spinal cord. These axons are prone to shearing forces and may be damaged during TBI, which could be a critical factor leading to depression in patients with TBI.

The manifestations of depression might be related to the site of cortical injury, because the site of a brain injury may determine the expression of depression [21,211-215]. Post-TBI lethargic depression appears to be related to left anterior hemispheric lesions, while right hemispheric lesions are associated with anxious depression. Lateral lesions are more likely to produce depression than are medial lesions. Medial frontal injury may produce emotional dysregulation or inhibit experience of mood changes. Patients with left hemispheric strokes are also more prone to depression [21]. Patients with moderate to severe TBI who develop mood disorders have significantly smaller hippocampal volumes than patients with equivalently severe TBI who do not develop mood disturbance [224]. Fatigue is also a common symptom in patients with TBI. While fatigue and lethargy may be symptoms of depression, they may exist also as independent entities and may be directly related to the brain injury itself [225]. The neural correlates of lethargy and fatigue are not known at this time. Intensity of fatigue in patients with TBI in first- and second-year follow-up studies shows little attenuation [226].

Criteria and Assessment. Depression criteria are defined with use of DSM-IV-TR criteria, although many variations of depression are listed. The recognition of depression must begin with a patient or caregiver complaint or clinician vigilance. A variety of depression scales is useful for screening, evaluating, and measuring depression.
However, the capability of psychological instruments to detect depression in patients with TBI varies considerably. In individuals with TBI, the Beck Depression Inventory has a sensitivity of 36 percent and a specificity of 80 percent [227]. Jorge et al. found that four symptoms consistently differentiated depressed from nondepressed individuals with TBI [211-215]: depressed mood, feelings of worthlessness, reduced energy, and suicidal ideation. They also found that early awakening and difficulty concentrating distinguished groups only after 6 months, suggesting that the nature of a post-TBI depressive disorder may change over time. The most accurate items to detect TBI-related depression that are present in the DSM-IV-TR-based Neurobehavioral Functioning Inventory are reduced libido, anhedonia, reduced appetite, and lack of confidence [209]. Suicide risk should be carefully assessed in all TBI cases.

Treatment Options. A paucity of TBI-related depression management trials exists. Most early studies of patients with TBI with depression examined the efficacy of tricyclic antidepressants, such as amitriptyline [228] (nortriptyline would offer all the benefits of this medication without as much anticholinergic side effect), and monoamine oxidase inhibitors, such as phenelzine [229], neither of which demonstrated efficacy in treating TBI-related melancholic depression. Desipramine, predominantly a norepinephrine reuptake inhibitor, however, clinically improved depression significantly [230]. Few studies have evaluated the efficacy of SSRIs in treating TBI-related depression. Statistically, sertraline significantly improved psychological distress, anger, and aggression [231]. Citalopram response and remission rates following treatment of patients with TBI were comparable with patients with depression and without TBI [232]. While these studies are helpful, insufficient evidence exists for developing standards of treatment for TBI-related depression. Other antidepressants such as bupropion, mirtazapine, venlafaxine, and duloxetine remain to be explored in treating TBI-related depression. At present, the clinician must determine treatment. Large multicenter clinical trials are needed to establish practice parameters. Psychostimulants, such as methylphenidate, have long been used as adjuncts in treating depression, and they have been advocated for use in patients with TBI [233]. In patients with human immunodeficiency virus, fatigue may be incapacitating and is significantly ameliorated with a psychostimulant, subsequently improving QOL [226] this benefit may also extend to individuals with TBI who experience fatigue with or without depression. 


\section{Affect}

Definition and Neurobiological Basis. DSM-IV-TR criteria are also used for defining manifestations of mania when they occur after TBI. The incidence of post-TBI mania is 9 percent [211-215], and the prevalence is 0.8 to 22 percent [234-236]. Risk factors include seizures, prolonged PTA, and varied lesion types including multifocal, orbitofrontal, temporal, and nondominant hemispheric lesions [237-239].

Criteria and Assessment. Patients with post-TBIrelated mania typically present with sleeplessness, grandiosity, impaired judgment, irritability, pressured speech (80\%-100\% of cases), hyperactivity (65\%), and hypersexual behavior (50\%) [234]. The majority of manic cases develop after at least 1 year post-TBI, and some studies have reported a delay of 4 to 5 years post-TBI $[234,240]$.

Several approaches have been used for diagnosing post-TBI mania based on the Research Diagnostic Criteria, DSM-III (Third Edition), DSM-III-Revised, and DSM-IV-TR. See Kim et al. for full discussion [21].

Treatment Options. Common approaches for treating mania, namely lithium [241] and valproate [242], have been shown to be effective in TBI-related mania. The possibility has also been raised that lithium can not only improve neuronal function but also stabilize behavior. Furthermore, lithium has been shown to increase gray matter volume [243]. Clinically in the population with non-TBI, antiseizure medications such as carbamazepine, oxcarbazepine, topiramate, and lamotragine are used off-label as mood stabilizers. Lamotragine is also FDA-approved for the maintenance treatment of bipolar mood disorder. Several atypical antipsychotics now carry FDA approval for the treatment of bipolar disorder, including aripiprazole, olanzapine, ziprazadone, and quietapine. Combinations of several of these medications have also been studied in patients with mania and found to be effective. Of particular interest is the option of using low-dose lithium as a neuroprotective medication with antisuicidal features [244], along with other agents so that the chronic toxicity of lithium can be minimized. However, the effectiveness of any of these medications in the treatment of TBI-related mania has not been established.

\section{PTSD and Other Anxiety Disorders}

Definition and Neurobiological Basis. Civilians with a history of TBI compared with those without TBI have increased risk ratios (RRs) for PTSD $(\mathrm{RR}=1.8)$, generalized anxiety disorder $(\mathrm{RR}=2.3)$, obsessive compulsive disorder $(\mathrm{RR}=2.6)$, and panic disorder $(\mathrm{RR}=5.8)$ [245]. Following TBI, a 13 to 27 percent incidence [29,246-248] and 3 to 59 percent prevalence of PTSD can be found [249-251]. The wide range reported for prevalence is likely due in part to the diverse manifestations of PTSD concerning TBI [21].

Among veterans, a strong relationship also exists between TBI and PTSD. OIF/OEF soldiers with mild TBI are likely to develop PTSD soon after their return home [252]. While 11 percent of returning soldiers screen positive for PTSD, of those with mild TBI, 62 percent screen positive for PTSD [253]. Thus, the occurrence of PTSD and related disorders may be much higher in veterans with combat-related TBI. A significant question has been asked about the interaction between TBI and PTSD. The evidence indicates that many symptoms of mild TBI are related to the development of PTSD, and in particular, PTSD is an important mediator of the relationship between mild TBI and physical health problems [252]. Further questions need to be addressed as to whether combatrelated mild TBI is more likely to cause particular neurological damage that will predispose to PTSD or whether the increased incidence of PTSD is related to premorbid or environmental factors, such as the stress of combat.

As defined by the DSM-IV-TR, PTSD is classified as an anxiety disorder that is induced by hypersensitive response to threat and includes reexperiencing, avoidance, and numbing. PTSD has also been considered a disorder of memory organization and may involve the intrinsic, nondeclarative amygdala-based memory processing systems and the extrinsic, declarative, hippocampal-based memoryprocessing systems. Patients with PTSD typically present with intrusive memories, fragmentation of autobiographical memories, fragmentation of trauma-related memories, deficits in declarative memory, and the presence of traumarelated amnesia [254]. The linking of PTSD to anxiety and memory is not necessarily a conflict, but rather suggests that many of the involved brain systems are interrelated.

Elzinga and Bremner have proposed that the neural substrates of memory may be a final common pathway of PTSD neuropathophysiology [254]. Memory information details are stored throughout the cortex, mainly posterior to the central sulcus. The storage of information is mediated by reciprocal connections between the cortex and the hippocampus (autobiographical and semantic memory) and amygdala (emotional conditioning). Since memory is a cognitive domain, PTSD has also been framed within a cognitive model that is still compatible with 
concepts of an anxiety disorder since anxiety is the result of cognitive appraisal of a threat. PTSD may become persistent when individuals process the trauma in a way that leads to a sense of serious current threat due to negative appraisals of the trauma and a disturbance of autobiographical memory characterized by poor elaboration and poor contextualization, strong associative memory, and strong perceptual priming [255].

Another consideration is that basic neurophysiological mechanisms may alter serotonergic learning pathways, which cause reexperiencing, particularly with nightmares [256]. Additionally, norepinephrine mechanisms, affecting levels of alertness and reward-orientation, may be involved in PTSD pathophysiology [257]. Of particular interest is that norepinephrine and serotonin medications are useful in treating depression and PTSD [256-257]. Norepinephrine and serotonin neuron cell bodies that project throughout the cortex are located in the brain stem, and their axons course through the medial forebrain bundle. Their axons are small, unmyelinated fibers and may be particularly vulnerable to shearing forces, which occur in some types of TBI. Consequently, TBI damage to these neurons could result in symptoms of PTSD and depression. The linking of these monoaminergic systems to PTSD, along with involvement of memory systems in the temporal lobe, including the amygdala and hippocampus, parallels the disruption of brain systems seen in AD [34,258], which may be causally related to TBI [259].

TBI can cause neurodegeneration in many brain structures, notably the hippocampus, cortex, and thalamus $[63,260]$. PTSD is also linked to decreased hippocampal volume. An ongoing debate exists as to whether PTSD can damage the hippocampus through stress effects or whether individuals with a smaller hippocampus are more prone to develop PTSD [261]. Regarding the relationship between TBI and PTSD, TBI may damage hippocampal connections enough to prime the system for future development of PTSD. Known risk factors for PTSD include LOC following a TBI [262], the presence of acute stress disorder following a TBI, and poor coping skills [29].

Criteria and Assessment. The criteria for diagnosing PTSD are outlined in DSM-IV-TR, and these criteria are the basis for scales that assess for the presence of PTSD. Using standard diagnostic tools that require "reexperiencing” symptoms to diagnose PTSD is problematic concerning TBI $[8,21]$ because memory impairment during and following TBI is common. Thus, while reexperiencing may be central in diagnosing PTSD, it may not be a presenting symptom in individuals suffering from PTSD who have comorbid TBI. Thus, the use of unmodified DSMIV-TR criteria and associated rating scales, such as the Present State Examination and Structured Clinical Interview, will subsequently produce a significant number of false negatives. Adding an additional scale, such as the Impact Event Scale, in memory loss cases may be useful to increase diagnostic sensitivity [246].

Treatment Options. PTSD has been suggested to become persistent when the traumatic stress is processed so that it leads to a sense of current threat resulting from improperly encoded autobiographical memory and perceptual priming. Changes in negative appraisal and the trauma memory are prevented by certain problematic behavioral and cognitive strategies [255], the targets of cognitive behavioral therapy. During the process of reappraisal, negative emotions are cognitively reframed to reduce physiological arousal without affecting the memory. In contrast, behavioral regulation suppresses negative emotions with a subsequent controlling of the traumatic memory, but an associated increase in sympathetic output may occur once the memory is experienced.

The SSRIs are the most widely studied and best tolerated medications for treating PTSD. These medications are significantly more effective than placebo and have been shown to significantly reduce core symptoms of PTSD (reexperiencing, avoidance, numbing, and hyperarousal). In addition to better tolerance than older antidepressants, they also appear more effective for PTSD [263]. Trazodone, a serotonergic agent, has been widely prescribed for patients with PTSD, both to control and reduce nightmares and to alleviate anxiety during the daytime [256]. Prazosin, a noradrenergic alpha-1 blocker, has also been used to reduce nightmares and daytime anxiety $[257,264]$. Propranolol, a centrally acting noradrenergic beta-blocker, has also been used to reduce anxiety. The benefits of these medications support the concept that both serotonergic and noradrenergic pathways are involved in the hyperarousal and adverse remembering associated with PTSD, and this insight can help manage chronic PTSD symptoms. Neuroleptics have been studied in PTSD treatment, and the typical dopaminergic blocking agents are considered detrimental to patients with PTSD, in spite of the psychotic proportions that the symptoms can manifest [265]. However, the atypical neuroleptics, with serotonergic effects, have some use [266]. Finally, sedative hypnotics (e.g., benzodiazepines) can temporarily relieve symptoms, but rebound symptoms and dependence contraindicate these medications for PTSD treatment. 
JRRD, Volume 46, Number 6, 2009

\section{Psychosis}

Definition and Neurobiological Basis. The incidence of psychosis following TBI is approximately 20 percent [267]; the prevalence has not been determined. Diagnosing psychosis following a TBI falls into the DSM-IV-TR classification of psychosis secondary to a general medical condition. This characterization, however, has been used inconsistently across studies and has significant limitation [21]. Because the average time between a TBI and the development of psychosis is 12 years, the causal relationship versus an idiopathic psychosis in patients with a history of TBI is unclear without further understanding the pathophysiology underlying post-TBI psychosis.

The range of psychotic disorders is detailed in DSM-IVTR. However, psychosis occurs in many variations and may be caused by numerous different and possibly unrelated pathophysiological mechanisms operating in the brain.

Dopamine is produced in the substantia nigra, the ventral tegmental area of the midbrain, and the arcuate nucleus of the hypothalamus. Unlike serotonergic and noradrenergic axons, the dopaminergic neurons that project to the cerebrum only target the basal ganglia and frontal cortex. They too are unmyelinated and may be several centimeters long. Because of their length and fragility, they may also be prone to axonal sheering. A psychotic manifestation in TBI may be due to a combination of certain risk factors, including left temporal lobe injuries, duration of LOC, TBI before adolescence, a genetic predisposition to schizophrenia [268], and a prior history of substance abuse and cognitive impairment [269-270]. A positive family history of psychosis and lengthy duration of LOC are the strongest predictors of the development of schizophrenia-like psychosis after TBI.

Criteria and Assessment. Psychosis following TBI typically involves positive-type symptoms, mainly paranoid delusions and auditory hallucinations [268]. Clinicians have used positive versus negative symptoms to differentiate TBI-related psychosis and the development of schizophrenia. This approach is problematic because patients with frontal lobe lesions present with significant negative-type symptoms, such as apathy.

To assess for the presence of psychosis, the clinician poses questions regarding positive symptoms (hallucinations, paranoia, and delusions) and negative symptoms (anhedonia and blunting of affect). The nature and extent of the injury, prior history of head injury, substance abuse, or psychological trauma are factors that must be considered when psychosis is assessed. Psychological testing is usually not required, although in equivocal cases, a Minnesota Multiphasic Personality Inventory may be helpful.

Treatment Options. Atypical and typical antipsychotics are the primary agents used for treating psychosis, the choice based on clinical judgment. The literature does not define any guidelines for treating TBI-related psychosis. A few case studies are available for the use of individual atypical antipsychotics [271-272], but comprehensive studies have not been reported.

\section{Agitation and Aggression}

Definition and Neurobiological Basis. The term "agitation" refers to nonpurposeful behaviors and can include aggressive behavior, physically nonaggressive behavior, and verbally agitated behavior [273]. Agitation may be viewed as low frustration tolerance that may culminate in an act of aggression. Loosely, impulsive aggression has been defined as a persistent uncontrolled loss of temper manifested by verbal outbursts, striking, throwing, and damaging property or attacks on other persons [274]. While neither aggression nor agitation is a syndrome, agitation is a part of several syndromes, such as depression, mania, and delirium. The DSM-IV-TR diagnostic criteria for PDGMC partially capture the phenomenon of aggression in patients with TBI. Intermittent explosive disorder, however, is a diagnosis that cannot be made in the presence of TBI.

The incidence of TBI-related aggression is 34 percent [275-276], while its prevalence ranges from 20 to 40 percent [277]. Agitation occurs frequently during the acute stages of recovery following TBI and may be seen in 35 to 96 percent of individuals $[13,278]$.

Numerous risk factors predispose to the development of agitation and aggression. Preinjury predictors of post-TBI aggression include family dysfunction, history of mood disorders, low socioeconomic status, and alcohol and substance abuse. A childhood history of oppositional-defiant behavior also predisposes to post-TBI aggression, which may be an extension of premorbid impulsivity and aggression [274]. Patients with such a risk-factor history showed increasing aggression with time as opposed to those patients without a risk-factor history [275]. While injury severity correlates with cognitive deficits, accordingly, many behavior problems after TBI, including aggression after TBI, do not correlate with levels of post-TBI aggression [21]. Effective screening of risk factors, especially childhood psychiatric history, helps identify patients with high risk for more intensive screening, follow-up, and treatment. 
Criteria and Assessment. Agitation may complicate and prolong a hospital stay and be associated with decreased cognition [279]. Agitation and aggression may persist, causing considerable disability in the workplace and at home. Individuals demonstrating agitation following TBI are frequently diagnosed with a bipolar disorder. Although bipolar disorder and TBI-related aggression both share irritability and dysphoria, the clinician should consider specific mood symptoms, such as increased energy, decreased sleep, pressured speech, and racing thoughts, to differentiate the two syndromes. Agitation and aggression are also seen following injury to the orbitofrontal lobe, a region that is specifically responsible for inhibiting primal drives such as aggression and libido. No DSM-IV-TR classification captures aggressive outbursts as a pure entity concerning TBI.

Instruments used in the assessment of TBI-related aggression include the Overt Aggression Scale, with 38 percent accuracy at 6 months [276], and the DeBlois Aggressive and Antisocial Behavior Scale, mainly used in children demonstrating an increase in aggression and antisocial behavior. Both the Overt Aggression Scale and the Neurobehavioral Rating Scale are effective for monitoring changes across time.

Treatment Options. Extensive publications examine the use of various pharmacological agents in treating aggression; most studies are limited in their study design, thus precluding the development of standards of treatment. Evidence does exist for the use of beta-blockers such as propranolol and pindolol for treating aggression in patients with TBI [4]. Clonidine, an alpha-2 antagonist, has long been used in children with ADHD who continue to behave aggressively in spite of using a stimulant. Furthermore, studies providing evidence for optional considerations include the use of methylphenidate, SSRIs, valproate, lithium, tricyclic antidepressants, and buspirone. For full details see Warden et al. [4].

\section{Sexual Health and Libido}

Despite the high prevalence of sexual dysfunction following head injury, a paucity of information exists describing these problems and their treatment for soldiers with TBI returning from war. Problems frequently encountered include impulsiveness or inappropriateness, changes in libido (particularly a decrease) and sexual frequency, global sexual difficulties, and specific sexual dysfunctions [280]. The etiology of sexual dysfunction is likely multifactorial in nature and should also be examined biopsychosocially.
Posttraumatic hypopituitarism is the failure of the hypothalamic-pituitary axis secondary to TBI. Clinically hypopituitarism may present with decreased muscle mass and libido, infertility, and electrolyte abnormalities, such as hyponatremia. In addition, patients may also present with fatigue, depression, and a variety of cognitive deficits. Posttraumatic hypopituitarism is a diagnosis based on clinical evaluation, laboratory testing, and neuroimaging [281].

Subjects with TBI frequently describe a discrepancy between preinjury "self" and postinjury "self." Cloute et al. discuss the importance of the reconstruction of identity following injury [282]. Schopp et al. described the masculine role functioning in life domains such as vocational functioning, sexual and interpersonal functioning, and personal independence [283]. Particular masculine role variables corresponded to different functional and psychological outcomes. Understanding these differences may provide new direction for treatment and may offer important information about aspects of traditional masculine roles that could enhance adjustment to injury.

One concern in managing the libido changes in patients with TBI is to carefully assess the medication regimen that a patient may have. For example, many antidepressant medications are well known to adversely affect sexual desire. Many other medications may similarly affect libido or other aspects of sexual function and, thus, should be used judiciously in patients with TBI.

\section{Somatosensory Disruptions}

Injury to sensory organs or their projections through the brain stem and elsewhere is frequently seen following TBI and may also be caused by axonal shearing. Each sensory organ system should be independently evaluated, and day-to-day functional impairments resulting from such injury should be delineated. Issues regarding olfactory, visual, and auditory senses will be outlined briefly:

- Olfactory dysfunction and disorders of taste have been well documented in conditions such as AD, Parkinson disease, and multiple sclerosis, but they remain to be fully characterized in TBI. Fibers from the nasal epithelium running through the cribriform plate to the olfactory bulb are vulnerable to trauma, particularly shearing. Disruption of these fibers may account for the frequent symptom of anosmia in patients with TBI and substantially alter the perception of taste. Also, the olfactory bulbs project through three branches to the basal forebrain and medial temporal lobe limbic areas, which are regions involved in motivation, emotion, and memory. In 
animal models, bulbectomy procedures cause depression and immune changes [284]. Consequently, changes in the sense of smell may alter emotions and social interactions as well as immune function.

- Visual disturbances such as anomalies of accommodation as evidenced by either intermittent or constant blurred vision may be present. Patients with TBI may also present with anomalies of vision such as abnormal saccades, pursuit, and fixation, which impact reading efficacy. Patients with TBI may complain of skipping lines inadvertently, which can greatly reduce reading speed and ultimately affect occupational functioning. They may also present with anomalies of vergence, which may cause in intermittent or constant diploplia and a sense the print is floating. Anomalies of the visual field result in spatial perceptual deficits. Anomalies of light sensitivity such as photosensitivity and photophobia may also be present [285].

- Auditory problems are potentially extensive. They can relate to damage to the ear, particularly the peripheral association of traumatic disruption of the tympanic membrane or the cochlea. Damage to delicate auditory pathways can also occur. Tinnitus is a particularly common and difficult-to-manage complaint but may be related to cerebral processing.

Another frequent problem in patients with TBI is dizziness. Dizziness most likely results from damage to the middle ear (vestibular apparatus), which includes the semicircular canals that respond to rotations and the otolithic organs that respond to sense linear accelerations with otoconia crystals. Either system could be damaged by external physical forces causing rapid translation or rotation of the head, permanently disturbing equilibrium. Note that dizziness may be caused by other TBI-associated problems, including disturbance of other neural systems and vascular damage.

\section{Somatic Symptoms - Headache and Chronic Pain Syndromes}

Chronic pain syndromes, such as headache, are an underdiagnosed consequence of TBI. Among civilians, the prevalence of chronic pain was greater in patients with mild TBI compared with those with moderate or severe TBI. Twenty studies including 3,289 civilian patients with TBI yielded a chronic pain prevalence of 52 percent. Three studies assessing TBI among 917 veterans yielded a pain prevalence of 43 percent. PTSD may mediate some TBI physical health symptoms, but brain injury appears to correlate independently with chronic pain [252]. Chronic pain is independent of psychological disorders such as PTSD and depression and is common even among patients with apparently minor injuries to the brain [286]. More research is needed to understand the treatment of chronic pain concerning mild TBI.

\section{Substance Dependence}

A common problem in most societies and among veterans of all conflicts is substance dependence. Substance dependence ranges from legitimate substance overuse, including tobacco and alcohol, to illicit substance use, including narcotics, stimulants (particularly methamphetamine and cocaine), sedative hypnotics, and hallucinogenics (marijuana, LSD [lysergic acid diethylamide], phencyclidine). Substance dependence also includes use that is deleterious to the long-range health and function of an individual, even if substance is legitimately prescribed by a licensed clinician. Commonly prescribed drugs of particular concern include narcotics and benzodiazepines. Clinicians need to consider substance dependence in patients with TBI for two reasons. First, TBI may predispose the patient to developing substance dependence because of weakened self-control or somatic pains that lead to excessive use of a substance, followed by dependence. Second, the patient with a TBI can be more impaired by substances because of deficiencies in brain function. Thus, a critical issue of which the primary-treating clinicians in the chronic care environment need to be aware is the possibility of substance dependence. They need to be alert to recognize the signs and symptoms. Also, clinicians should try to avoid the use of chronic narcotic and benzodiazepine prescriptions in these patients.

\section{DISCUSSION}

Cognitive dysfunctions (memory, attention, language, visuospatial cognition, sensory-motor integration, affect recognition, and executive function), neurobehavioral disorders (mood, affect, anxiety, posttraumatic stress, psychotic, sleep, and libidinal disorders), somatosensory disruptions (changes in smell, vision, hearing, equilibrium, taste, and somatosensory perception), somatic symptoms (headache, chronic pain), and substance dependence (in the context of a post-TBI occurrence or relapse) define symptom clusters observed in many veterans returning from OIF/ OEF (Figure 1). Social and occupational dysfunctions 
and the reduction in QOL may be attributed to any component of the post-TBI state; therefore, each facet of TBI should be fully evaluated for the need of a comprehensive and individualized treatment plan. While cognitive dysfunction and neurobehavioral disorders may be due to a circuitry interruption involving the cortex and subcortical structures, somatic symptoms are most likely due to damage to specific sensory organs or their projections. Approaching the myriad of post-TBI psychiatric symptoms as discrete clusters will help clinicians facilitate rehabilitation and ensure that neurology and psychiatry resources know the goals for each specialty, thereby providing comprehensive diagnosis and care and minimizing the risk of missing significant problems in patients with TBI.

Various rating scales and their sensitivities in detecting psychiatric sequelae concerning TBI have been discussed only briefly. Many traditional psychiatric rating scales are problematic concerning a TBI. For example, scales used to detect PTSD may not be sufficiently sensitive in those patients with TBI, because these scales rely heavily on reexperiencing phenomena for diagnosis, which may be absent because of PTA. Syndromal criteria and instruments of detection need to be redefined for individuals with TBI, and rating scales need to be further developed using Modern Test Theory ${ }^{*}$ so that they can be efficiently applied in the clinical setting. Until further study of patients with TBI is conducted to provide specific understanding of TBI ramifications, clinicians need to be vigilant for both typical and atypical presentations of various chronic neuropsychiatric sequelae of TBI.

Once delineated, capturing symptoms on a five-axis DSM-IV-TR diagnosis is problematic in view of the multitude of available diagnostic classifications. MNI may be used to capture cognitive sequelae as an axis I diagnosis. Neurobehavioral sequelae can be captured using standard taxonomies for mood, anxiety, and psychotic disorders until the taxonomies are revised to include specific presentations of these disorders concerning TBI. Somatic symptoms can be evaluated as a single entity and listed on axis III. No clear evidence exists to establish a link between a specific cogni-

\footnotetext{
*Modern Test Theory refers to "Item Response Theory" and "Item Characteristic Curve Analysis" and is the approach used for all modern tests, such as the Scholastic Aptitude and intelligence quotient tests. However, this approach is not widely used in places where it could be of great use, such as "Modern Medicine." More information can be found in Reise SP, Haviland MG. Item response theory and the measurement of clinical change. J Pers Assess. 2005;84(3):228-38. [PMID: 15907159]
}

tive dysfunction and specific somatic symptoms. Dizziness, for example, may be associated with memory impairment in one individual and with language difficulties in another. To foster efficient care of the patient with TBI, the primary care physician should consider the biopsychosocial approach and coordinate the care of the patient with a unique presentation, working with a team that includes psychiatrists, neurologists, and rehabilitation medicine physicians, as well as psychologists and social workers to fully assess each component of the cognitive dysfunctions, neurobehavioral disorders, somatosensory disruptions, and somatic symptoms, as well as any possibility of substance dependence or other related problem.

For the most part, clearly, inadequate evidence-based data exist to support specific treatments for the neuropsychiatric sequelae of TBI. Consequently, treatment considerations are based on experience with analogous conditions. Stimulants (notably, methylphenidate) have been studied in the treatment of frontal lobe dysfunction (attention, impulsivity, and hyperactivity). The Texas Medication Algorithm Project, while outlining a six-step treatment approach for ADHD, may be applied to individuals with TBI-related ADHD-type symptoms. Using this algorithm in individuals with TBI who present with ADHD-type symptoms could help establish the use of ADHD medications in treating TBI-related inattention, impulsivity, and hyperactivity. The Texas Medication Algorithm Project also provides additional treatment options of ADHD-associated comorbidities, such as depression, anxiety, and aggression. Medications that promote neurogenesis are a promising new modality that needs significant investigation. The critical issue in recovery from TBI is restoration of neurobiological function, and neuroplasticity is a fundamental mechanism that must be used in rehabilitation. Although medications may be less useful for fostering redevelopment of function, they may facilitate the intensive relearning of lost skills and abilities. In every case, integration of attention to the spectrum of biopsychosocial factors and development of individualized treatment plans are likely to be the most beneficial approaches.

\section{CONCLUSIONS}

TBIs and the resulting symptoms are tragic, lifechanging events for many returning from the battlefield. Innovation in warfare technology has decreased the mortality of these soldiers, but as a result, incidents of TBI are being seen in unprecedented numbers. Because of the 
previous scarcity of these types of injuries, research on the symptoms, assessment, and treatment of TBI is limited. This article proposes a starting point and suggests ways for creating a differential diagnostic nosology that will help medical resources provide comprehensive treatment for both somatic and neuropsychiatric diagnoses that are common in patients with TBI. Further studies should be done on differential diagnostic models and the neurocognitive effects of TBI, as well as treatment approaches. As is clear from this article and others that have noted the lack of evidence on which to base diagnostic and management recommendations, formal studies of the incidence of specific sequelae of TBI are needed and research into the efficacy of probable treatment modalities is urgently indicated.

\section{ACKNOWLEDGMENTS}

\author{
Author Contributions: \\ Analysis and interpretation of data: J. A. Yesavage, J. W. Ashford, \\ J. D. Halbauer. \\ Drafting of manuscript: J. D. Halbauer, J. W. Ashford, J. M. Zeitzer. \\ Critical revision of manuscript for important intellectual content: \\ H. L. Lew, M. M. Adamson, J. A. Yesavage. \\ Supervisors of manuscript: J. W. Ashford, J. A. Yesavage, H. L. Lew. \\ Financial Disclosures: The authors have declared that no competing \\ interests exist. \\ Funding/Support: This material is the result of work supported with \\ resources and the use of facilities at the Medical Research Service of \\ the Department of Veterans Affairs (VA) Palo Alto Health Care Sys- \\ tem and the VA Sierra-Pacific Mental Illness Research, Education and \\ Clinical Center and War-Related Illness and Injury Study Center. The \\ content is solely the responsibility of the authors and does not neces- \\ sarily represent the official view of the VA.
}

Additional Contributions: This article was written as part of Dr. Halbauer's Mental Illness Research, Education and Clinical Center VA Advanced Fellowship Program in Mental Illness Research and Treatment.

Additional Information: Dr. Henry L. Lew is now with Harvard Medical School in Boston, Massachusetts.

\section{REFERENCES}

1. Hinsley DE, Rosell PA, Rowlands TK, Clasper JC. Penetrating missile injuries during asymmetric warfare in the 2003 Gulf conflict. Br J Surg. 2005;92(5):637-42.

[PMID: 15744703]

DOI:10.1002/bjs.4911

2. Wade AL, Dye JL, Mohrle CR, Galarneau MR. Head, face, and neck injuries during Operation Iraqi Freedom II: Results from the US Navy-Marine Corps Combat Trauma Registry.
J Trauma. 2007;63(4):836-40. [PMID: 18090014]

DOI:10.1097/01.ta.0000251453.54663.66

3. Teasdale TW, Engberg AW. Subjective well-being and quality of life following traumatic brain injury in adults: A long-term population-based follow-up. Brain Inj. 2005; 19(12):1041-48. [PMID: 16263647] DOI:10.1080/02699050500110397

4. Warden DL, Gordon B, McAllister TW, Silver JM, Barth JT, Bruns J, Drake A, Gentry T, Jagoda A, Katz DI, Kraus J, Labbate LA, Ryan LM, Sparling MB, Walters B, Whyte J, Zapata A, Zitnay G; Neurobehavioral Guidelines Working Group. Guidelines for the pharmacologic treatment of neurobehavioral sequelae of traumatic brain injury. J Neurotrauma. 2006;23(10):1468-1501. [PMID: 17020483] DOI:10.1089/neu.2006.23.1468

5. Peloso PM, Carrol LJ, Cassidy JD, Borg J, Von Holst H, Holm L, Yates D. Critical evaluation of the existing guidelines on mild traumatic brain injury. J Rehabil Med. 2004; 43 Suppl:106-12. [PMID: 15083974]

DOI:10.1080/16501960410023868

6. Carroll LJ, Cassidy JD, Peloso PM, Borg J, Von Holst H, Holm L, Paniak C, Pépin M; WHO Collaborating Centre Task Force on Mild Traumatic Brain Injury. Prognosis for mild traumatic brain injury: Results of the WHO Collaborating Centre Task Force on Mild Traumatic Brain Injury. J Rehabil Med. 2004;43 Suppl:84-105. [PMID: 15083873] DOI:10.1080/16501960410023859

7. Kay T, Harrington DE, Adams R, Anderson T, Berrol S, Cicerone K, Dahlberg C, Gerber D, Goka R, Harley P, Hilt J, Horn L, Lehmkuhl D, Malec J. Definition of mild traumatic brain injury. J Head Trauma Rehabil. 1993;8(3):86-87. DOI:10.1097/00001199-199309000-00010

8. Feinstein A, Hershkop S, Ouchterlony D, Jardine A, McCullagh S. Posttraumatic amnesia and recall of a traumatic event following traumatic brain injury. J Neuropsychiatry Clin Neurosci. 2002;14(1):25-30.

[PMID: 11884651] DOI:10.1176/appi.neuropsych.14.1.25

9. Borg J, Holm L, Cassidy JD, Peloso PM, Carrol LJ, Von Holst H, Ericson K; WHO Collaborating Center Task Force on Mild Traumatic Brain Injury. Diagnostic procedures in mild traumatic brain injury: Results of the WHO Collaborating Centre Task Force on Mild Traumatic Brain Injury. J Rehabil Med. 2004;43 Suppl:61-75. [PMID: 15083871] DOI:10.1080/16501960410023822

10. Comerford VE, Geffen GM, May C, Medland SE, Geffen LB. A rapid screen of the severity of mild traumatic brain injury. J Clin Exp Neuropsychol. 2002;24(4):409-19. [PMID: 12187455] DOI:10.1076/jcen.24.4.409.1044

11. De Monte VE, Geffen GM, May CR, McFarland K. Double cross-validation and improved sensitivity of the rapid screen of mild traumatic brain injury. J Clin Exp Neuropsychol. 
2004;26(5):628-44. [PMID: 15370385$]$

DOI:10.1080/13803390490504443

12. Shores EA. Further concurrent validity data on the Westmead PTA Scale. Appl Neuropsychol. 1995;2(3-4):167-69. [PMID: 16318522] DOI:10.1207/s15324826an0203\&4 11

13. Levin HS, O’Donnell VM, Grossman RG. The Galveston Orientation and Amnesia Test. A practical scale to assess cognition after head injury. J Nerv Ment Dis. 1979; 167(11):675-84. [PMID: 501342]

14. Forrester G, Encel J, Geffen G. Measuring post-traumatic amnesia (PTA): An historical review. Brain Inj. 1994;8(2): 175-84. [PMID: 8193637] DOI:10.3109/02699059409150969

15. Hughes DG, Jackson A, Mason DL, Berry E, Hollis S, Yates DW. Abnormalities on magnetic resonance imaging seen acutely following mild traumatic brain injury: Correlation with neuropsychological tests and delayed recovery. Neuroradiology. 2004;46(7):550-58. [PMID: 15185054] DOI:10.1007/s00234-004-1227-x

16. Kraus MF, Susmaras T, Caughlin BP, Walker CJ, Sweeney JA, Little DM. White matter integrity and cognition in chronic traumatic brain injury: A diffusion tensor imaging study. Brain. 2007;130(Pt 10):2508-19. [PMID: 17872928] DOI:10.1093/brain/awm216

17. Arfanakis K, Haughton VM, Carew JD, Rogers BP, Dempsey RJ, Meyerand ME. Diffusion tensor MR imaging in diffuse axonal injury. AJNR Am J Neuroradiol. 2002;23(5): 794-802. [PMID: 12006280]

18. Song SK, Sun SW, Ramsbottom MJ, Chang C, Russell J, Cross AH. Dysmyelination revealed through MRI as increased radial (but unchanged axial) diffusion of water. Neuroimage. 2002;17(3):1429-36. [PMID: 12414282] DOI:10.1006/nimg.2002.1267

19. Song SK, Sun SW, Ju WK, Lin SJ, Cross AH, Neufeld AH. Diffusion tensor imaging detects and differentiates axon and myelin degeneration in mouse optic nerve after retinal ischemia. Neuroimage. 2003;20(3):1714-22.

[PMID: 14642481]

DOI:10.1016/j.neuroimage.2003.07.005

20. Harsan LA, Poulet P, Guignard B, Steibel J, Parizel N, De Sousa PL, Boehm N, Grucker D, Ghandour MS. Brain dysmyelination and recovery assessment by noninvasive in vivo diffusion tensor magnetic resonance imaging. J Neurosci Res. 2006;83(3):392-402. [PMID: 16397901] DOI:10.1002/jnr.20742

21. Kim E, Lauterbach EC, Reeve A, Arciniegas DB, Coburn KL, Mendez MF, Rummans TA, Coffey EC; ANPA Committee on Research. Neuropsychiatric complications of traumatic brain injury: A critical review of the literature (a report by the ANPA Committee on Research). J Neuropsychiatry
Clin Neurosci. 2007;19(2):106-27. [PMID: 17431056]

DOI:10.1176/appi.neuropsych.19.2.106

22. Meares S, Shores EA, Taylor AJ, Batchelor J, Bryant RA, Baguley IJ, Chapman J, Gurka J, Dawson K, Capon L, Marosszeky JE. Mild traumatic brain injury does not predict acute postconcussion syndrome. J Neurol Neurosurg Psychiatry. 2008;79(3):300-306. [PMID: 17702772] DOI:10.1136/jnnp.2007.126565

23. Iverson GL, Zasler ND, Lang RT. Post-concussive disorder. In: Zasler ND, Katz DI, Zafonte RD, editors. Brain injury medicine: Principals and practice. New York (NY): Demos; 2007. p. 373-405.

24. Mittenberg W, DiGiulio DV, Perrin S, Bass AE. Symptoms following mild head injury: Expectation as aetiology. J Neurol Neurosurg Psychiatry. 1992;55(3):200-204. [PMID: 1564481]

DOI:10.1136/jnnp.55.3.200

25. Kashluba S, Casey JE, Paniak C. Evaluating the utility of ICD-10 diagnostic criteria for postconcussion syndrome following mild traumatic brain injury. J Int Neuropsychol Soc. 2006;12(1):111-18. [PMID: 16433950]

26. Luis C, Vanderploeg RD, Curtiss G. Predictors of postconcussion symptom complex in community dwelling male veterans. J Int Neuropsychol Soc. 2003;9(7):1001-15. [PMID: 14738282]

27. Landre N, Poppe CJ, Davis N, Schmaus B, Hobbs SE. Cognitive functioning and postconcussive symptoms in trauma patients with and without mild TBI. Arch Clin Neuropsychol. 2006;21(4):255-73. [PMID: 16716563] DOI:10.1016/j.acn.2005.12.007

28. McCauley SR, Boak C, Levin HS, Contant CF, Song JX. Postconcussional disorder following mild to moderate traumatic brain injury: Anxiety, depression, and social support as risk factors and comorbidities. J Clin Exp Neuropsychol. 2001;23(6):792-808. [PMID: 11910545] DOI:10.1076/jcen.23.6.792.1016

29. Bryant RA, Harvey AG. Relationship between acute stress disorder and posttraumatic stress disorder following mild traumatic brain injury. Am J Psychiatry. 1998; 155(5):625-29. [PMID: 9585713]

30. American Psychiatric Association. Diagnostic and statistical manual of mental disorders: DSM-IV-TR. 4th ed, text revision. Washington (DC): American Psychiatric Association; 2000.

31. Mirzayan MJ, Probst C, Krettek C, Samii M, Pape HC, Van Griensven M, Samii A. Systemic effects of isolated brain injury: An experimental animal study. Neurol Res. 2008;30(5):457-60. [PMID: 18953734]

32. Scheff SW, Price DA, Hicks RR, Baldwin SA, Robinson S, Brackney C. Synaptogenesis in the hippocampal CA1 field following traumatic brain injury. J Neurotrauma. 2005; 
22(7):719-32. [PMID: 16004576]

DOI:10.1089/neu.2005.22.719

33. Levin HS. Neuroplasticity following non-penetrating traumatic brain injury. Brain Inj. 2003;17(8):665-74.

[PMID: 12850951]

DOI:10.1080/0269905031000107151

34. Teter B, Ashford JW. Neuroplasticity in Alzheimer's disease. J Neurosci Res. 2002;70(3):402-37. [PMID: 12391603] DOI:10.1002/jnr.10441

35. Ashford JW. APOE genotype effects on Alzheimer's disease onset and epidemiology. J Mol Neurosci. 2004;23(3): 157-65. [PMID: 15181244]

DOI:10.1385/JMN:23:3:157

36. Raber J, Huang Y, Ashford JW. ApoE genotype accounts for the vast majority of $\mathrm{AD}$ risk and $\mathrm{AD}$ pathology. Neurobiol Aging. 2004;25(5):641-50. [PMID: 15172743]

DOI:10.1016/j.neurobiolaging.2003.12.023

37. Zhou W, Xu D, Peng X, Zhang Q, Jia J, Crutcher KA. Meta-analysis of APOE4 allele and outcome after traumatic brain injury. J Neurotrauma. 2008;25(4):279-90.

[PMID: 18373478]

DOI:10.1089/neu.2007.0489

38. World Health Organization. International Classification of Functioning, Disability and Health (ICF). Geneva (Switzerland): World Health Organization; 2001.

39. Lindner MD, Plone MA, Cain CK, Frydel B, Francis JM, Emerich DF, Sutton RL. Dissociable long-term cognitive deficits after frontal versus sensorimotor cortical contusions. J Neurotrauma. 1998;15(3):199-216. [PMID: 9528920] DOI:10.1089/neu.1998.15.199

40. Ashford JW, Coburn KL, Fuster JM. Functional cognitive networks in primates. In: Parks RW, Levine DS, Long DL, editors. Fundamentals of neural networks: Neuropsychology and cognitive neuroscience. Cambridge (MA): MIT Press; 1998.

41. Fuster JM. The cognit: A network model of cortical representation. Int J Psychophysiol. 2006;60(2):125-32.

[PMID: 16626831]

DOI:10.1016/j.ijpsycho.2005.12.015

42. McClelland JL Complementary learning systems in the brain. A connectionist approach to explicit and imlicit cognition and memory. Ann N Y Acad Sci. 1998;843: 153-69. [PMID: 9668656] DOI:10.1111/j.1749-6632.1998.tb08212.x

43. Siegel DJ. Memory: An overview, with emphasis on developmental, interpersonal, and neurobiological aspects. J Am Acad Child and Adolesc Psychiatry. 2001;40(9):997-1011. [PMID: 11556645]

DOI:10.1097/00004583-200109000-00008

44. Squire LR. Memory and the hippocampus: A synthesis from findings with rats, monkeys, and humans. Psychol
Rev. 1992;99(2):195-231. [PMID: 1594723]

DOI:10.1037/0033-295X.99.2.195

45. Sim A, Terryberry-Spohr L, Wilson KR. Prolonged recovery of memory functioning after mild traumatic brain injury in adolescent athletes. J Neurosurg. 2008;108(3): 511-16. [PMID: 18312098]

DOI:10.3171/JNS/2008/108/3/0511

46. Ashford JW. Screening for memory disorder, dementia, and Alzheimer's disease. Aging Health. 2008;4(4):399-432.

DOI:10.2217/1745509X.4.4.399

47. Lezak MD, Loring DW, Howieson DB. Neuropsychological assessment. 4th ed. New York (NY): Oxford University Press; 2004.

48. Strauss E, Sherman EM, Spreen O. Compendium of neuropsychological tests: Administration, norms, and commentary. 3rd ed. New York (NY): Oxford University Press; 2006.

49. Weintraub S. Neuropsychological assessment of mental state. In: Mesulam MM, editor. Principles of behavioral and cognitive neurology. 2nd ed. New York (NY): Oxford University Press; 2000. p. 121-73.

50. Marklund N, Bakshi A, Castelbuono DJ, Conte V, McIntosh TK. Evaluation of pharmacological treatment strategies in traumatic brain injury. Curr Pharm Des. 2006; 12(13):1645-80. [PMID: 16729876]

DOI:10.2174/138161206776843340

51. McIntosh TK, Vink R, Noble L, Yamakami I, Fernyak S, Soares H, Faden AL. Traumatic brain injury in the rat: Characterization of a lateral fluid-percussion model. Neuroscience. 1989;28(1):233-44. [PMID: 2761692]

DOI:10.1016/0306-4522(89)90247-9

52. Taverni JP, Seliger G, Lichtman SW. Donepezil medicated memory improvement in traumatic brain injury during post acute rehabilitation. Brain Inj. 1998;12(1):77-80. [PMID: 9483340] DOI:10.1080/026990598122881

53. Masanic CA, Bayley MT, VanReekum R, Simard M. Openlabel study of donepezil in traumatic brain injury. Arch Phys Med Rehabil. 2001;82(7):896-901. [PMID: 11441374] DOI:10.1053/apmr.2001.23833

54. Zhang L, Plotkin RC, Wang G, Sandel ME, Lee S. Cholinergic augmentation with donepezil enhances recovery in short-term memory and sustained attention after traumatic brain injury. Arch Phys Med Rehabil. 2004;85(7):1050-55. [PMID: 15241749]

DOI:10.1016/j.apmr.2003.10.014

55. Foster M, Spiegel DR. Use of donepezil in the treatment of cognitive impairments of moderate traumatic brain injury. J Neuropsychiatry Clin Neurosci. 2008;20(1):106. [PMID: 18305293] DOI:10.1176/appi.neuropsych.20.1.106 
56. Silver JM, Koumaras B, Chen M, Mirski D, Potkin SG, Reyes P, Warden D, Harvey PD, Arciniegas D, Katz DI, Gunay I. Effects of rivastigmine on cognitive function in patients with traumatic brain injury. Neurology. 2006; 67(5):748-55. [PMID: 16966534] DOI:10.1212/01.wnl.0000234062.98062.e9

57. Wilcock G, Howe I, Coles H, Lilienfeld S, Truyen L, Zhu Y, Bullock R, Kershaw P; GAL-GBR-2 Study Group. A long-term comparison of galantamine and donepezil in the treatment of Alzheimer's disease. Drugs Aging. 2003; 20(10):777-89. [PMID: 12875613] DOI:10.2165/00002512-200320100-00006

58. Rao VL, Dogan A, Todd KG, Bowen KK, Dempsey RJ. Neuroprotection by memantine, a non-competitive NMDA receptor antagonist after traumatic brain injury in rats. Brain Res. 2001;911(1):96-100. [PMID: 11489449] DOI:10.1016/S0006-8993(01)02617-8

59. Battista MA, Hierholzer R, Khouzam HR, Barlow A, O'Toole S. Pilot trial of memantine in the treatment of posttraumatic stress disorder. Psychiatry. 2007;70(2):167-74. [PMID: 17661541] DOI:10.1521/psyc.2007.70.2.167

60. Mooney GF, Haas LJ. Effect of methylphenidate on brain injury-related anger. Arch Phys Med Rehabil. 1993;74(2): 153-60. [PMID: 8431099]

61. Speech TJ, Rao SM, Osmon DC, Sperry LT. A doubleblind controlled study of methylphenidate treatment in closed head injury. Brain Inj. 1993;7(4):333-38.

[PMID: 8358406] DOI:10.3109/02699059309034959

62. Kaneko N, Sawamoto K. [Neuronal migration in the adult brain]. Nihon Shinkei Seishin Yakurigaku Zasshi. 2007; 28(2):63-68. Japanese. [PMID: 18516984]

63. Bremner JD, Vermetten E. Neuroanatomical changes associated with pharmacotherapy in posttraumatic stress disorder. Ann N Y Acad Sci. 2004;1032:154-57. [PMID: 15677402] DOI:10.1196/annals.1314.012

64. Wexler EM, Geschwind DH, Palmer TD. Lithium regulates adult hippocampal progenitor development through canonical Wnt pathway activation. Mol Psychiatry. 2008; 13(3):285-92. [PMID: 17968353]

DOI:10.1038/sj.mp.4002093

65. Wada A, Yokoo H, Yanagita T, Kobayashi H. Lithium: Potential therapeutics against acute brain injuries and chronic neurodegenerative diseases. J Pharmacol Sci. 2005;99(4):307-21. [PMID: 16340157]

DOI:10.1254/jphs.CRJ05009X

66. Whyte J, Hart T, Vaccaro M, Grieb-Neff P, Risser A, Polansky M, Coslett HB. Effects of methylphenidate on attention deficits after traumatic brain injury: A multidimensional, randomized, controlled trial. Am J Phys Med
Rehabil. 2004;83(6):401-20. [PMID: 15166683]

DOI:10.1097/01.PHM.0000128789.75375.D3

67. Moscovitch M. Information processing and the cerebral hemispheres. In: Gazzaniga MS, editor. Neuropsychology. New York (NY): Plenum Press; 1979. p. 379-446. (Handbook of behavioral neurobiology; vol. 2).

68. Lewis M, editor. Child and adolescent psychiatry: A comprehensive textbook. 3rd ed. Philadelphia (PA): Lippincott Williams \& Wilkins; 2002.

69. Van Zomeren AH, Brouwer WH. Clinical neuropsychology of attention. New York (NY): Oxford University Press; 1994.

70. Margulies DM. Selective attention and the brain: A hypothesis concerning the hippocampal-Ventral striatal axis, the mediation of selective attention, and the pathogenesis of attentional disorders. Med Hypotheses. 1985; 18(3):221-64. [PMID: 3853081] DOI:10.1016/0306-9877(85)90027-1

71. Hunt R, Cohen DJ, Anderson G. Noradrenergic mechanisms in ADHD. In: Bloomingdale LM, editor. Attention deficit disorder and hyperactivity, Vol. 3. New York (NY): Spectrum; 1987.

72. Zametkin A, Rappoport JL. Noradrenergic hypothesis of attention deficit disorder with hyperactivity: A critical review. In: Meltzer HY, editor. Psychophramacology: The third generation of progress. New York (NY): Raven Press; 1987. p. 837-42.

73. Coburn KL, Ashford JW, Fuster JM. Visual response latencies in temporal lobe structures as a function of stimulus information load. Behav Neurosci. 1990;104(1):62-73.

[PMID: 2317287] DOI:10.1037/0735-7044.104.1.62

74. Fuster JM. Jackson and the frontal executive hierarchy. Int J Psychophysiol. 2007;64(1):106-7. [PMID: 16959349] DOI:10.1016/j.ijpsycho.2006.07.014

75. Mesulam MM. Large-scale neurocognitive networks and distributed processing for attention, language, and memory. Ann Neurol. 1990;28(5):597-613. [PMID: 2260847] DOI:10.1002/ana.410280502

76. Fernandez-Duque D, Posner MI. Brain imaging of attentional networks in normal and pathological states. J Clin Exp Neuropsychol. 2001;23(1):74-93. [PMID: 11320446] DOI:10.1076/jcen.23.1.74.1217

77. Fan J, McCandliss BD, Sommer T, Raz A, Posner MI. Testing the efficiency and independence of attentional networks. J Cogn Neurosci. 2002;14(3):340-47. [PMID: 11970796] DOI:10.1162/089892902317361886

78. Doyle R. The history of adult attention-deficit/hyperactivity disorder. Psychiatr Clin North Am. 2004;27(2):203-14. [PMID: 15063993] DOI:10.1016/j.psc.2004.01.001 
79. Goodman D. Treatment and assessment of ADHD in adults. In: Biederman J, editor. ADHD Across the life span: From research to clinical practice-An evidencebased understanding. Hasbrouck Heights (NJ): Veritas Institute for Medical Education, Inc; 2005.

80. Whyte J, Hart T, Ellis CA, Chervoneva I. The Moss Attention Rating Scale for traumatic brain injury: Further explorations of reliability and sensitivity to change. Arch Phys Med Rehabil. 2008;89(5):966-73. [PMID: 18452747] DOI:10.1016/j.apmr.2007.12.031

81. Stroop JR. Studies of interference in serial verbal reactions. J Exp Psychol. 1935;18:643-62. DOI:10.1037/h0054651

82. Reitan R. Validity of the Trail Making Test as an indication for organic brain damage. Percept Mot Skills. 1958; 8:271-76. DOI:10.2466/PMS.8.7.271-276

83. Van Zomeren AH. Reaction time and attention after closed head injury. Lisse (the Netherlands): Swets \& Zeitlinger; 1981.

84. Van Zomeren AH, Deelman BG. Long-term recovery of visual reaction time after closed head injury. J Neurol Neurosurg Psychiatry. 1978;41(5):452-57. [PMID: 660209] DOI:10.1136/jnnp.41.5.452

85. Gronwall, DM, Sampson HD. The psychological effects of concussion. Auckland (New Zealand): Auckland University Press; 1974.

86. Gronwall DM. Paced auditory serial-addition task: A measure of recovery from concussion. Percept Mot Skills. 1977;44(2):367-73. [PMID: 866038$]$

87. Tombaugh TN. A comprehensive review of the Paced Auditory Serial Addition Test (PASAT). Arch Clin Neuropsychol. 2006;21(1):53-76. [PMID: 16290063] DOI:10.1016/j.acn.2005.07.006

88. Tombaugh TN, Rees L, Stormer P, Harrison AG, Smith A. The effects of mild and severe traumatic brain injury on speed of information processing as measured by the computerized tests of information processing (CTIP). Arch Clin Neuropsychol. 2007;22(1):25-36. [PMID: 17071052] DOI:10.1016/j.acn.2006.06.013

89. Nelson HE. A modified card sorting test sensitive to frontal lobe defects. Cortex. 1976;12(4):313-24. [PMID: 1009768]

90. Deelman BG, Brouwer WH, Van Zomeren AH, Saan RJ. [Deficiencies in functioning following trauma capitis]. In: Jennekens-Schinkel A, editor. [Neuropsychology in the Netherlands]. Deventer (the Netherlands): Loghum Slaterus; 1980. p. 253-81. Dutch.

91. Spikman JM, Kiers HA, Deelman BG, Van Zomeren AH. Construct validity of concepts of attention in healthy controls and patients with CHI. Brain Cogn. 2001;47(3):446-60.

[PMID: 11748900]

DOI:10.1006/brcg.2001.1320

92. Brouwer WH, Van Wolffelaar PC. Sustained attention and sustained effort after closed head injury: Detection and
$0.10 \mathrm{~Hz}$ heart rate variability in a low event rate vigilance task. Cortex. 1985;21(1):111-19. [PMID: 3987305]

93. Miller E. Simple and choice reaction time following severe head injury. Cortex. 1970;6(1):121-27. [PMID: 5426573]

94. Zoccolotti P, Matano A, Deloche G, Cantagallo A, Passadori A, Leclercg M, Braga L, Cremel N, Pittau P, Renom M, Rousseaux M, Trauche A, Fim B, Zimmermann P. Patterns of attentional impairment following closed head injury: A collaborative European study. Cortex. 2000;36(1):93-107. [PMID: 10728900] DOI:10.1016/S0010-9452(08)70839-6

95. Spikman JM, Van Zomeren AH, Deelman BG. Deficits of attention after closed-head injury: Slowness only? J Clin Exp Neuropsychol. 1996;18(5):755-67. [PMID: 8941860] DOI:10.1080/01688639608408298

96. Van Zomeren AH, Van den Burg W. Residual complaints of patients two years after severe head injury. J Neurol Neurosurg Psychiatry. 1985;48(1):21-28. [PMID: 3973618] DOI:10.1136/jnnp.48.1.21

97. Pliszka SR, Greenhill LL, Crismon ML, Sedillo A, Carlson C, Conners CK, McCracken JT, Swanson JM, Hughes CW, Llana ME, Lopez M, Toprac MG. The Texas Children's Medication Algorithm Project: Report of the Texas consensus conference panel on medication treatment of childhood attention-deficit/hyperactivity disorder. Part I. Attentiondeficit/hyperactivity disorder. J Am Acad Child Adolesc Psychiatry. 2000;39(7):908-19. [PMID: 10892234] DOI:10.1097/00004583-200007000-00021

98. Pliszka SR, Greenhill LL, Crismon ML, Sedillo A, Carlson C, Conners CK, McCracken JT, Swanson JM, Hughes CW, Llana ME, Lopez M, Toprac MG. The Texas Children's Medication Algorithm Project: Report of the Texas consensus conference panel on medication treatment of childhood attention-deficit/hyperactivity disorder. Part II: Tactics. Attention-deficit/hyperactivity disorder. J Am Acad Child Adolesc Psychiatry. 2000;39(7):920-27. [PMID: 10892235] DOI:10.1097/00004583-200007000-00022

99. Pliszka SR, Browne RG, Olvera RL, Wynne SK. A doubleblind, placebo-controlled study of Adderall and methylphenidate in the treatment of attention-deficit/hyperactivity disorder. J Am Acad Child Adolesc Psychiatry. 2000;39(5): 619-26. [PMID: 10802980] DOI:10.1097/00004583-200005000-00016

100. Pliszka S, Dodson WW, Spencer TJ. Current treatments of attention-deficit/hyperactivity disorder. CNS Spectr. 2000; 5(5 Suppl 3):S1-7. [PMID: 18268469]

101. Pliszka SR, Liotti M, Woldorff MG. Inhibitory control in children with attention-deficit/hyperactivity disorder: Eventrelated potentials identify the processing component and timing of an impaired right-frontal response-inhibition mechanism. Biol Psychiatry. 2000;48(3):238-46.

[PMID: 10924667]

DOI:10.1016/S0006-3223(00)00890-8 
102. Pliszka SR. Pharmacologic treatment of attention-deficit/ hyperactivity disorder: Efficacy, safety and mechanisms of action. Neuropsychol Rev. 2007;17(1):61-72.

[PMID: 17242993]

DOI:10.1007/s11065-006-9017-3

103. Plenger PM, Dixon CE, Castillo RM, Frankowski RF, Yablon SA, Levin HS. Subacute methylphenidate treatment for moderate to moderately severe traumatic brain injury: A preliminary double-blind placebo-controlled study. Arch Phys Med Rehabil. 1996;77(6):536-40.

[PMID: 8831468]

DOI:10.1016/S0003-9993(96)90291-9

104. Kaelin DL, Cifu DX, Matthies B. Methylphenidate effect on attention deficit in the acutely brain-injured adult. Arch Phys Med Rehabil. 1996;77(1):6-9. [PMID: 8554476] DOI:10.1016/S0003-9993(96)90211-7

105. Hornstein A, Lennihan L, Seliger G, Lichtman S, Schroeder $\mathrm{K}$. Amphetamine in recovery from brain injury. Brain Inj. 1996;10(2):145-48. [PMID: 8696315]

DOI:10.1080/026990596124647

106. Napolitano E, Elovic EP, Qureshi AI. Pharmacological stimulant treatment of neurocognitive and functional deficits after traumatic and non-traumatic brain injury. Med Sci Monit. 2005;11(6):RA212-20. [PMID: 15917733]

107. Ripley DL. Atomoxetine for individuals with traumatic brain injury. J Head Trauma Rehabil. 2006;21(1):85-88.

[PMID: 16456396] DOI:10.1097/00001199-200601000-00010

108. Payen D, Quintin L, Plaisance P, Chiron B, Lhoste F. Head injury: Clonidine decreases plasma catecholamines. Crit Care Med. 1990;18(4):392-95. [PMID: 2180636]

109. Biederman J, Petty CR, Fried R, Kaiser R, Dolan CR, Schoenfeld S, Doyle AE, Seidman LJ, Faraone SV. Educational and occupational underattainment in adults with attention-deficit/hyperactivity disorder: A controlled study. J Clin Psychiatry. 2008;69(8):1217-22. [PMID: 18681752]

110. Findling RL, McNamara NK, Stansbrey RJ, Maxhimer R, Periclou A, Mann A, Graham SM. A pilot evaluation of the safety, tolerability, pharmacokinetics, and effectiveness of memantine in pediatric patients with attention-deficit/ hyperactivity disorder combined type. J Child Adolesc Psychopharmacol. 2007;17(1):19-33. [PMID: 17343551] DOI:10.1089/cap.2006.0044

111. Sawyer E, Mauro LS, Ohlinger MJ. Amantadine enhancement of arousal and cognition after traumatic brain injury. Ann Pharmacother. 2008;42(2):247-52. [PMID: 18212258] DOI:10.1345/aph.1K284

112. Kraus MF, Maki PM. Effect of amantadine hydrochloride on symptoms of frontal lobe dysfunction in brain injury: Case studies and review. J Neuropsychiatry Clin Neurosci. 1997;9(2):222-30. [PMID: 9144101]
113. Whyte J, Vaccaro M, Grieb-Neff P, Hart T, Polansky M, Coslett HB. The effects of bromocriptine on attention deficits after traumatic brain injury: A placebo-controlled pilot study. Am J Phys Med Rehabil. 2008;87(2):85-99.

[PMID: 18209510] DOI:10.1097/PHM.0b013e3181619609

114. Heilman KM, Safran A, Geschwind N. Closed head trauma and aphasia. J Neurol Neurosurg Psychiatry. 1971; 34(3):265-69. [PMID: 5571313$]$ DOI:10.1136/jnnp.34.3.265

115. Sarano MT, Buonaguro A, Levita E. Characteristics of verbal impairment after closed head injured patients. Arch Phys Med Rehabil. 1986;67(6):400-405. [PMID: 2424401]

116. Sarno MT. The nature of verbal impairment after closed head injury. J Nerv Ment Dis. 1980;168(11):685-92. [PMID: 7441232] DOI:10.1097/00005053-198011000-00008

117. McDonald S, Togher L, Code C. Communication disorders following traumatic brain injury. Hove (United Kingdom): Psychology Press; 1999.

118. Angeleri R, Bosco FM, Zettin M, Sacco K, Colle L, Bara BG. Communicative impairment in traumatic brain injury: A complete pragmatic assessment. Brain Lang. 2008; 107(3):229-45. [PMID: 18267340$]$

DOI:10.1016/j.bandl.2008.01.002

119. Geschwind N. The organization of language and the brain. Science. 1970;170(961):940-44. [PMID: 5475022] DOI:10.1126/science.170.3961.940

120. Waxman SG. Clinical neuroanatomy. 25th ed. New York (NY): Lange Medical Books/McGraw-Hill; 2003. p. 267-69.

121. Ylvisaker M, Szekeres S, Feeney TJ. Communication disorders associated with traumatic brain injury. In: Chapey $\mathrm{R}$, editor. Language intervention strategies in adult aphasia. 5th ed. Baltimore (MD): Williams \& Wilkins; 2000. p. 745-800.

122. Milton SB, Prutting CA, Binder GM. Appraisal of communicative competence in head injured adults. Clinical aphasiology conference; 1984 May 20-24; Seabrook Island, South Carolina. Minneapolis (MN): BRK Publisher; 1984. p. 114-23.

123. Prigatano G, Roueche J, Fordyce D. Nonaphasic language disturbances after brain injury. In: Prigatano GP, Fordyce DJ, Zeiner HK, Roueche JR, Pepping M, Wood BC, editors. Neuropsychological rehabilitation after brain injury. Baltimore (MD): John Hopkins University Press; 1986.

124. Hartley LL. Cognitive-communicative abilities following brain injury: A functional approach. San Diego (CA): Singular; 1995.

125. Davis G. Aphasiology: Disorders and clinical practice. Boston (MA): Allyn and Bacon; 2000.

126. Ylvisaker M, Hanks R, Johnson-Greene D. Perspectives on rehabilitation of individuals with cognitive impairment after 
brain injury: Rationale for reconsideration of theoretical paradigms. J Head Trauma Rehabil. 2002;17(3):191-209. [PMID: 12086574]

DOI:10.1097/00001199-200206000-00002

127. Brooks N, McKinlay W, Symington C, Beattie A, Campsie L. Return to work within the first seven years of severe head injury. Brain Inj. 1987;1(1):5-19. [PMID: 3454672] DOI:10.3109/02699058709034439

128. Godfrey HP, Shaum D. Executive functioning and the application of social skills following traumatic brain injury. Aphasiology. 2000;14(4):433-44. DOI:10.1080/026870300401441

129. Godfrey HP, Bishara SN, Partridge FM, Knight RG. Neuropsychological impairment and return to work following severe closed head injury: Implications for clinical management. N Z Med J. 1993;106(960):301-3. [PMID: 8341452]

130. Godfrey HP, Knight RG, March NV, Moroney B, Bishara SN. Social interaction and speed of information processing following very severe head-injury. Psychol Med. 1989; 19(1):175-82. [PMID: 2471219] DOI:10.1017/S0033291700011120

131. Penn C, Cleary J. Compensatory strategies in the language of closed head injured patients. Brain Inj. 1988; 2(1):3-17. [PMID: 245879] DOI:10.3109/02699058809150928

132. McDonald S, Flanagan S, Rollins J, Kinch J. TASIT: A new clinical tool for assessing social perception after traumatic brain injury. J Head Trauma Rehabil. 2003;18(3): 219-38. [PMID: 12802165] DOI:10.1097/00001199-200305000-00001

133. Larkins B. The application of the ICF in cognitive-communication disorders following traumatic brain injury. Semin Speech Lang. 2007;28(4):334-42. [PMID: 17935018] DOI:10.1055/s-2007-986530

134. Ylvisaker M, Szekeres S, Henry K, Sullivan D, Wheeler $\mathrm{P}$. Topics in cognitive rehabilitation therapy. In: Ylvisaker M, Gobble EM, editors. Community re-entry for head injured adults. Boston (MA): Little, Brown; 1987.

135. Bakheit AM. Drug treatment of poststroke aphasia. Expert Rev Neurother. 2004;4(2):211-17. [PMID: 15853562] DOI:10.1586/14737175.4.2.211

136. Korsukewitz C, Breitenstein C, Schomacher M, Knecht S. [Present status and future possibilities of adjuvant pharmacotherapy for aphasia]. Nervenarzt. 2006;77(4):403-15. German. [PMID: 16273340] DOI:10.1007/s00115-005-2006-6

137. De Boissezon X, Peran P, De Boysson C, Démonet JF. Pharmacotherapy of aphasia: Myth or reality? Brain Lang. 2007;102(1):114-25. [PMID: 16982084 DOI:10.1016/j.bandl.2006.07.004

138. Egan J, Worrall L, Oxenham D. An internet training intervention for people with traumatic brain injury: Barriers and outcomes. Brain Inj. 2005;19(8):555-68. [PMID: 16175810] DOI:10.1080/02699050400013659

139. Jordan LC, Hillis AE. Disorders of speech and language: Aphasia, apraxia and dysarthria. Curr Opin Neurol. 2006; 19(6):580-85. [PMID: 17102697] DOI:10.1097/WCO.0b013e3280109260

140. Pagulayan KF, Temkin NR, Machamer J, Dikmen SS. A longitudinal study of health-related quality of life after traumatic brain injury. Arch Phys Med Rehabil. 2006; 87(5):611-18. [PMID: 16635622] DOI:10.1016/j.apmr.2006.01.018

141. Jackson HF, Moffat NJ. Impaired emotional recognition following severe head injury. Cortex. 1987;23(2):293-300. [PMID: 3608522]

142. Hornak J, Bramham J, Rolls ET, Morris RG, O’Doherty J, Bullock PR, Polkey CE. Changes in emotion after circumscribed surgical lesions of the orbitofrontal and cingulate cortices. Brain. 2003;126(Pt 7):1691-1712. [PMID: 12805109] DOI:10.1093/brain/awg168

143. Spell LA, Frank E. Recognition of nonverbal communication of affect following traumatic brain injury. J Nonver Behav. 2000;24(4):285-300.

DOI:10.1023/A:1006675230193

144. Marquardt T, Rios-Brown M, Richburg T, Seibert LK, Cannito MP. Comprehension and expression of affective sentences in traumatic brain injury. Aphasiology. 2001; 15(10):1091-1101. DOI:10.1080/02687040143000429

145. Turkstra LS, McDonald S, DePompei R. Social information processing in adolescents: Data from normally developing adolescents and preliminary data from their peers with traumatic brain injury. J Head Trauma Rehabil. 2001; 16(5):469-83. [PMID: 11574042] DOI:10.1097/00001199-200110000-00006

146. Hopkins MJ, Dywan J, Segalowitz SJ. Altered electrodermal response to facial expression after closed head injury. Brain Inj. 2002;16(3):245-57. [PMID: 11874616] DOI:10.1080/02699050110103346

147. Milders M, Fuchs S, Crawford JR. Neuropsychological impairments and changes in emotional and social behaviour following severe traumatic brain injury. J Clin Exp Neuropsychol. 2003;25(2):157-72. [PMID: 12754675] DOI:10.1076/jcen.25.2.157.13642

148. Borgaro SR, Prigatano GP, Kwasnica C, Alcott S, Cutter N. Disturbances in affective communication following brain injury. Brain Inj. 2004;18(1):33-39. [PMID: 14660234$]$ DOI:10.1080/0269905031000110562

149. Green RE, Turner GR, Thompson WF. Deficits in facial emotion perception in adults with recent traumatic brain injury. Neuropsychologia. 2004;42(2):133-41.

[PMID: 14644100]

DOI:10.1016/j.neuropsychologia.2003.07.005 
150. Guercio JM, Podolska-Schroeder H, Rehfeldt RA. Using stimulus equivalence technology to teach emotion recognition to adults with acquired brain injury. Brain Inj. 2004;18(6):593-601. [PMID: 15204339]

DOI:10.1080/02699050310001646116

151. McDonald S, Flanagan S. Social perception deficits after traumatic brain injury: Interaction between emotion recognition, mentalizing ability, and social communication. Neuropsychology. 2004:18(3):572-79. [PMID: 15291735] DOI:10.1037/0894-4105.18.3.572

152. McDonald S. Putting communication disorders in context after traumatic brain injury. Aphasiology. 2000;14(4): 339-47. DOI:10.1080/026870300401397

153. Rolls ET, Hornak J, Wade D, McGrath J. Emotion-related learning in patients with social and emotional changes associated with frontal lobe damage. J Neurol Neurosurg Psychiatry. 1994;57(12):1518-24. [PMID: 7798983] DOI:10.1136/jnnp.57.12.1518

154. Nowicki S Jr, Duke MP. Individual differences in the nonverbal communication of affect: The diagnostic analysis of nonverbal accuracy scale. J Nonverbal Behav. 1994; 18(1):9-35. DOI:10.1007/BF02169077

155. Grossman JB, Klin A, Carter AS, Volkmar FR. Verbal bias in recognition of facial emotions in children with Asperger syndrome. J Child Psychol Psychiatry. 2000; 41(3):369-79. [PMID: 10784084]

DOI:10.1111/1469-7610.00621

156. Schultz RT, Gauthier I, Klin A, Fulbright RK, Anderson AW, Volkmar F, Skudlarski P, Lacadie C, Cohen DJ, Gore JC. Abnormal ventral temporal cortical activity during face discrimination among individuals with autism and Asperger syndrome. Arch Gen Psychiatry. 2000;57(4): 331-40. [PMID: 10768694]

DOI:10.1001/archpsyc.57.4.331

157. Phillips ML, Drevets WC, Rauch SL, Lane R. Neurobiology of emotion perception I: The neural basis of normal emotion perception. Biol Psychiatry. 2003;54(5):504-14. [PMID: 12946879]

DOI:10.1016/S0006-3223(03)00168-9

158. Ogai M, Matsumoto H, Suzuki K, Ozawa F, Fukuda R, Uchiyama I, Suckling J, Isoda H, Mori N, Takei N. fMRI study of recognition of facial expressions in highfunctioning autistic patients. Neuroreport. 2003;14(4): 559-63. [PMID: 12657885] DOI:10.1097/00001756-200303240-00006

159. Wang AT, Dapretto M, Hariri AR, Sigman M, Bookheimer SY. Neural correlates of facial affect processing in children and adolescents with autism spectrum disorder. J Am Acad Child Adolesc Psychiatry. 2004;43(4):481-90.

[PMID: 15187809]

DOI:10.1097/00004583-200404000-00015
160. Radice-Neumann D, Zupan B, Babbage DR, Willer B. Overview of impaired facial affect recognition in persons with traumatic brain injury. Brain Inj. 2007;21(8):807-16. [PMID: 17676438] DOI:10.1080/02699050701504281

161. LoBello SG, Underhil AT, Valentine PV, Stroud TP, Bartolucci AA, Fine PR. Social integration and life and family satisfaction in survivors of injury at 5 years postinjury. J Rehabil Res Dev. 2003;40(4):293-99. [PMID: 15074440]

162. Testa JA, Malec JF, Moessner AM, Brown AW. Predicting family functioning after TBI: Impact of neurobehavioral factors. J Head Trauma Rehabil. 2006;21(3):236-47.

[PMID: 16717501] DOI:10.1097/00001199-200605000-00004

163. Gan C, Campbell KA, Gemeinhardt M, McFadden GT. Predictors of family system functioning after brain injury. Brain Inj. 2006;20(6):587-600. [PMID: 16754284] DOI:10.1080/02699050600743725

164. Riley GA. Stress and depression in family carers following traumatic brain injury: The influence of beliefs about difficult behaviours. Clin Rehabil. 2007;21(1):82-88.

[PMID: 17213245]

DOI:10.1177/0269215506071279

165. Wedcliffe T, Ross E. The psychological effects of traumatic brain injury on the quality of life of a group of spouses/partners. S Afr J Commun Disord. 2001;48:77-99. [PMID: 14968697

166. Wood RL, Liossi C, Wood L. The impact of head injury neurobehavioural sequelae on personal relationships: Preliminary findings. Brain Inj. 2005;19(10):845-51.

[PMID: 16175844$]$

DOI:10.1080/02699050500058778

167. Hall GB, Szechtman H, Nahmias C. Enhanced salience and emotion recognition in autism: A PET study. Am J Psychiatry. 2003;160(8):1439-41. [PMID: 12900306] DOI:10.1176/appi.ajp.160.8.1439

168. Piggot J, Kwon H, Mobbs D, Blasey C, Lotspeich L, Menon V, Bookheimer S, Reiss AL. Emotional attribution in high-functioning individuals with autistic spectrum disorder: A functional imaging study. J Am Acad Child Adolesc Psychiatry. 2004;43(4):473-80. [PMID: 15187808] DOI:10.1097/00004583-200404000-00014

169. Weeks SJ, Hobson RP. The salience of facial expression for autistic children. J Child Psychol Psychiatry. 1987; 28(1):137-51. [PMID: 3558531] DOI:10.1111/j.1469-7610.1987.tb00658.x

170. Hornak J, Rolls ET, Wade D. Face and voice expression identification in patients with emotional and behavioural changes following ventral frontal lobe damage. Neuropsychologia. 1996;34(4):247-61. [PMID: 8657356$]$ DOI:10.1016/0028-3932(95)00106-9 
171. Blair RJ, Morris JS, Frith CD, Perrett DI, Dolan RJ. Dissociable neural responses to facial expressions of sadness and anger. Brain. 1999;122(Pt 5):883-93. [PMID: 10355673] DOI:10.1093/brain/122.5.883

172. Hoffman EA, Haxby JV. Distinct representations of eye gaze and identity in the distributed human neural system for face perception. Nat Neurosci. 2000;3(1):80-84. [PMID: 10607399] DOI:10.1038/71152

173. Adolphs RG, Gosselin F, Buchanan TW, Tranel D, Schyns P, Damasio AR. A mechanism for impaired fear recognition after amygdala damage. Nature. 2005;433(7021):68-72. [PMID: 15635411] DOI:10.1038/nature03086

174. Tarr MJ, Gauthier I. FFA: A flexible fusiform area for subordinate-level visual processing automatized by expertise. Nat Neurosci. 2000;3(8):764-69. [PMID: 10903568] DOI:10.1038/77666

175. Haxby JV, Hoffman EA, Gobbini MI. The distributed human neural system for face perception. Trends Cogn Sci. 2000;4(6):223-33. [PMID: 10827445] DOI:10.1016/S1364-6613(00)01482-0

176. Adolphs RG, Tranel D, Damasio AR. The human amygdala in social judgment. Nature. 1998;393(6684):470-74.

[PMID: 9624002]

DOI:10.1038/30982

177. Broks P, Young AW, Maratos EJ, Coffey PJ, Calder AJ, Isaac CL, Mayes AR, Hodges JR, Montaldi D, Cezayirli E, Roberts N, Hadley D. Face processing impairments after encephalitis: Amygdala damage and recognition of fear. Neuropsychologia. 1998;36(1):59-70. [PMID: 9533388] DOI:10.1016/S0028-3932(97)00105-X

178. Scott SK, Young AW, Calder AJ, Hellawell DJ, Aggleton JP, Johnsons M. Impaired auditory recognition of fear and anger following bilateral amygdala lesions. Nature. 1997; 385(6613):254-57. [PMID: 9000073] DOI:10.1038/385254a0

179. Vuilleumier P. Cognitive science: Staring fear in the face. Nature. 2005;433(7021):22-23. [PMID: 15635392] DOI:10.1038/433022a

180. Leekam SR, Libby SJ, Wing L, Gould J, Taylor C. The Diagnostic Interview for Social and Communication Disorders: Algorithms for ICD-10 childhood autism and Wing and Gould autistic spectrum disorder. J Child Psychol Psychiatry. 2002;43(3):327-42. [PMID: 11944875$]$ DOI:10.1111/1469-7610.00024

181. Bartolo A, Weisbecker A, Coello Y. Linguistic and spatial information for action. Behav Brain Res. 2007;184(1):19-30. [PMID: 17681618] DOI:10.1016/j.bbr.2007.06.011
182. Hutt ML. The Kohs Block-design tests: A revision for clinical practice. J Appl Psychol. 1932;16(3):298-307.

DOI:10.1037/h0074559

183. Ashman TA, Cantor JB, Gordon WA, Sacks A, Spielman L, Egan M, Hibbard MR. A comparison of cognitive functioning in older adults with and without traumatic brain injury. J Head Trauma Rehabil. 2008;23(3):139-48. [PMID: 18520426]

184. Cicerone KD, Mott T, Azulay J, Sharlow-Galella MA, Ellmo WJ, Paradise S, Friel JC. A randomized controlled trial of holistic neuropsychologic rehabilitation after traumatic brain injury. Arch Phys Med Rehabil. 2008;89(12): 2239-49. [PMID: 19061735$]$ DOI:10.1016/j.apmr.2008.06.017

185. Smania N, Girardi F, Domenicali C, Lora E, Aglioti S. The rehabilitation of limb apraxia: A study in left-braindamaged patients. Arch Phys Med Rehabil. 2000;81(4): 379-88. [PMID: 10768524] DOI:10.1053/mr.2000.6921

186. Graham DI, Raghupathi R, Saatman KE, Meaney D, McIntosh TK. Tissue tears in the white matter after lateral fluid percussion brain injury in the rat: Relevance to human brain injury. Acta Neuropathol. 2000;99(2):117-24.

[PMID: 10672317] DOI:10.1007/PL00007414

187. Reid-Arndt SA, Nehl C, Hinkebein J. The Frontal Systems Behaviour Scale (FrSBe) as a predictor of community integration following a traumatic brain injury. Brain Inj. 2007;21(13-14):1361-69. [PMID: 18066938] DOI:10.1080/02699050701785062

188. Cummings JL. Frontal-subcortical circuits and human behavior. Arch Neurol. 1993;50(8):873-80. [PMID: 8352676$]$

189. Brown TE. ADD/ADHD and impaired executive function in clinical practice. Curr Psychiatry Rep. 2008;10(5):407-11. [PMID: 18803914] DOI:10.1007/s11920-008-0065-7

190. Wallesch CW, Curio N, Galazky I, Jost S, Synowitz H. The neuropsychology of blunt head injury in the early postacute stage: Effects of focal lesions and diffuse axonal injury. J Neurotrauma. 2001;18(1):11-20. [PMID: 112100246] DOI:10.1089/089771501750055730

191. Hanks RA, Rapport LJ, Millis SR, Deshpande SA. Measures of executive functioning as predictors of functional ability and social integration in a rehabilitation sample. Arch Phys Med Rehabil. 1999;80(9):1030-37. [PMID: 10489004$]$ DOI:10.1016/S0003-9993(99)90056-4

192. Millis SR, Rosenthal M, Lourie IF. Predicting community integration after traumatic brain injury with neuropsychological measures. Int J Neurosci. 1994;79(3-4): 165-67. [PMID: 7744558] 
193. Lehtonen S, Stringer AY, Millis S, Boake C, Englander J, Hart T, High W, Macciocchi S, Meythaler J, Novack T, Whyte J. Neuropsychological outcome and community re-integration following traumatic brain injury: The impact of frontal and non-frontal lesions. Brain Inj. 2005; 19(4):239-56. [PMID: 15832870] DOI:10.1080/0269905040004310

194. Mazaux JM, Masson F, Levin HS, Alaoui P, Maurette P, Barat M. Long-term neuropsychological outcome and loss of social autonomy after traumatic brain injury. Arch Phys Med Rehabil. 1997;78(12):1316-20. [PMID: 9421984$]$ DOI:10.1016/S0003-9993(97)90303-8

195. Kim E. Agitation, aggression, and disinhibition syndromes after traumatic brain injury. NeuroRehabilitation. 2002;17(4):297-310. [PMID: 12547978$]$

196. Van den Broek M. Cognitive rehabilitation and traumatic brain injury. Rev Clin Gerontol. 1999;9:257-64. DOI:10.1017/S0959259899009363

197. Gioia GA, Isquith PK, Guy SC, Kenworthy L. Behavior rating inventory of executive function. Child Neuropsychol. 2000;6(3):235-38. [PMID: 11419452] DOI:10.1076/chin.6.3.235.3152

198. Grace J, Malloy PF. Frontal systems behavior scale: Professional manual. Lutz (FL): Psychological Assessment Resources, Inc; 2000.

199. Malloy P, Grace J. A review of rating scales for measuring behavior change due to frontal systems damage. Cogn Behav Neurol. 2005;18(1):18-27. [PMID: 15761273] DOI:10.1097/01.wnn.0000152232.47901.88

200. Ready RE, Ott BR, Grace J, Cahn-Weiner DA. Apathy and executive dysfunction in mild cognitive impairment and Alzheimer disease. Am J Geriatr Psychiatry. 2003; 11(2):222-28. [PMID: 12611752]

201. Verdejo-García A, Rivas-Pérez C, López-Torrecillas F, Pérez-García M. Differential impact of severity of drug use on frontal behavioral symptoms. Addict Behav. 2006;31(8):1373-82. [PMID: 16326022]

DOI:10.1016/j.addbeh.2005.11.003

202. Spinella M, Yang B, Lester D. Prefrontal system dysfunction and credit card debt. Int J Neurosci. 2004;114(10): 1323-32. [PMID: 15370189] DOI:10.1080/00207450490476011

203. Flavell JH, Green FL, Flavell ER. Children's understanding of the stream of consciousness. Child Dev. 1993;64(2): 387-98. [PMID: 8477624]

DOI:10.2307/1131257

204. Bivona U, Ciurli P, Barba C, Onder G, Azicnuda E, Silvestro D, Mangano R, Rigon J, Formisano R. Executive function and metacognitive self-awareness after severe traumatic brain injury. J Int Neuropsychol Soc. 2008; 14(5):862-68. [PMID: 18764981] DOI:10.1017/S1355617708081125
205. Toglia J, Kirk U. Understanding awareness deficits following brain injury. NeuroRehabilitation. 2000;15(1):57-70. [PMID: 11455082]

206. McDowell S, Whyte J, D’Esposito M. Differential effect of a dopaminergic agonist on prefrontal function in traumatic brain injury patients. Brain. 1998;121(Pt 6):1155-64. [PMID: 9648550] DOI:10.1093/brain/121.6.1155

207. Rapoport MJ, McCullagh S, Shammi P, Feinstein A. Cognitive impairment associated with major depression following mild and moderate traumatic brain injury. J Neuropsychiatry Clin Neurosci. 2005;17(1):61-65. [PMID: 15746484$]$ DOI:10.1176/appi.neuropsych.17.1.61

208. Rapoport MJ, McCullagh S, Steiner D, Feinstein A. The clinical significance of major depression following mild traumatic brain injury. Psychosomatics. 2003;44(1):31-37. [PMID: 12515835$]$ DOI:10.1176/appi.psy.44.1.31

209. Kreutzer JS, Seel RT, Gourley E. The prevalence and symptom rates of depression after traumatic brain injury: A comprehensive examination. Brain Inj. 2001;15(7): 563-76. [PMID: 11429086] DOI:10.1080/02699050010009108

210. Seel RT, Kreutzer JS. Depression assessment after traumatic brain injury: An empirically based classification method. Arch Phys Med Rehabil. 2003;84(11):1621-28. [PMID: 14639561] DOI:10.1053/S0003-9993(03)00270-3

211. Jorge RE, Robinson RG, Arndt SV. Are there symptoms that are specific for depressed mood in patients with traumatic brain injury? J Nerv Ment Dis. 1993;181(2):91-99. [PMID: 8426177] DOI:10.1097/00005053-199302000-00004

212. Jorge RE, Robinson RG, Arndt SV, Forrester AW, Geisler F, Starkstein SE. Comparison between acute- and delayedonset depression following traumatic brain injury. J Neuropsychiatry Clin Neurosci. 1993;5(1):43-49.

[PMID: 8428134]

213. Jorge RE, Robinson RG, Arndt SV, Starkstein SE, Forrester AW, Geisler F. Depression following traumatic brain injury: A 1 year longitudinal study. J Affect Disord. 1993;27(4):233-43. [PMID: 8509524] DOI:10.1016/0165-0327(93)90047-N

214. Jorge RE, Robinson RG, Starkstein SE, Arndt SV. Depression and anxiety following traumatic brain injury. J Neuropsychiatry Clin Neurosci. 1993;5(4):369-74. [PMID: 8286933]

215. Jorge RE, Robinson RG, Starkstein SE, Arndt SV, Forrester AW, Geisler FH. Secondary mania following traumatic brain injury. Am J Psychiatry. 1993;150(6):916-21. [PMID: 8494069] 
216. Jorge RE, Robinson RG, Moser D, Tateno A, CrespoFacorro B, Arndt SV. Major depression following traumatic brain injury. Arch Gen Psychiatry. 2004;61(1):42-50.

[PMID: 14706943]

DOI:10.1001/archpsyc.61.1.42

217. Heron MP. Deaths: Leading causes for 2004. National vital statistics reports; Vol. 56, No. 5. Hyattsville (MD): National Center for Health Statistics; 2007.

218. Simpson G, Tate R. Suicidality in people surviving a traumatic brain injury: Prevalence, risk factors and implications for clinical management. Brain Inj. 2007;21(13-14): 1335-51. [PMID: 18066936] DOI:10.1080/02699050701785542

219. Carr JR, Hoge CW, Gardner J, Potter R. Suicide surveillance in the U.S. Military-Reporting and classification biases in rate calculations. Suicide Life Threat Behav. 2004;34(3):233-41. [PMID: 15385178] DOI:10.1521/suli.34.3.233.42785

220. Kleck G. Miscounting suicides. Suicide Life Threat Behav. 1988;18(3):219-36. [PMID: 3188138]

221. O'Carroll PW. A consideration of the validity and reliability of suicide mortality data. Suicide Life Threat Behav. 1989;19(1):1-16. [PMID: 2652382]

222. Phillips DP, Ruth TE. Adequacy of official suicide statistics for scientific research and public policy. Suicide Life Threat Behav. 1993;23(4):307-19. [PMID: 8310465]

223. Eaton KM, Messer SC, Garvey Wilson AL, Hoge CW. Strengthening the validity of population-based suicide rate comparisons: An illustration using U.S. military and civilian data. Suicide Life Threat Behav. 2006;36(2):182-91.

[PMID: 16704323]

DOI:10.1521/suli.2006.36.2.182

224. Jorge RE, Acion L, Starkstein SE, Magnotta V. Hippocampal volume and mood disorders after traumatic brain injury. Biol Psychiatry. 2007;62(4):332-38. [PMID: 17123480] DOI:10.1016/j.biopsych.2006.07.024

225. Cantor JB, Ashman T, Gordon W, Ginsberg A, Engmann C, Egan M, Spielman L, Dijkers M, Flanagan S. Fatigue after traumatic brain injury and its impact on participation and quality of life. J Head Trauma Rehabil. 2008;23(1): 41-51. [PMID: 18219234] DOI:10.1097/01.HTR.0000308720.70288.af

226. Bushnik T, Englander J, Wright J. The experience of fatigue in the first 2 years after moderate-to-severe traumatic brain injury: A preliminary report. J Head Trauma Rehabil. 2008;23(1):17-24. [PMID: 18219231] DOI:10.1097/01.HTR.0000308717.80590.22

227. Sliwinski M, Gordon WA, Bogdany J. The Beck Depression Inventory: Is it a suitable measure of depression for individuals with traumatic brain injury? J Head Trauma Rehabil. 1998;13(4):40-46. [PMID: 9651238] DOI:10.1097/00001199-199808000-00004
228. Dinan TG, Mobayed M. Treatment resistance of depression after head injury: A preliminary study of amitriptyline response. Acta Psychiatr Scand. 1992;85(4):292-94.

[PMID: 1595364$]$ DOI:10.1111/j.1600-0447.1992.tb01472.x

229. Saran AS. Depression after minor closed head injury: Role of dexamethasone suppression test and antidepressants. J Clin Psychiatry. 1985;46(8):335-38.

[PMID: 4019422]

230. Wroblewski BA, Joseph AB, Cornblatt RR. Antidepressant pharmacotherapy and the treatment of depression in patients with severe traumatic brain injury: A controlled, prospective study. J Clin Psychiatry. 1996;57(12):582-87. [PMID: 9010122]

231. Fann JR, Uomoto JM, Katon WJ. Sertraline in the treatment of major depression following mild traumatic brain injury. J Neuropsychiatry Clin Neurosci. 2000;12(2):226-32. [PMID: 11001601] DOI:10.1176/appi.neuropsych.12.2.226

232. Rapoport MJ, Chan F, Lanctot K, Herrmann N, McCullagh S, Feinstein A. An open-label study of citalopram for major depression following traumatic brain injury. J Psychopharmacol. 2008;22(8):860-64. [PMID: 18208921] DOI:10.1177/0269881107083845

233. Challman TD, Lipsky JJ. Methylphenidate: Its pharmacology and uses. Mayo Clin Proc. 2000;75(7):711-21.

[PMID: 10907387] DOI:10.4065/75.7.711

234. Shukla S. Cook BL, Mukherjee S, Godwin C, Miller MG. Mania following head trauma. Am J Psychiatry. 1987; 144(1):93-96. [PMID: 3799847]

235. Van Reekum R, Bolago I, Finlayson MA, Garner S, Links PS. Psychiatric disorders after traumatic brain injury. Brain Inj. 1996;10(5):319-27. [PMID: 8735663] DOI:10.1080/026990596124340

236. Varney N, Martzke JS, Roberts RJ. Major depression in patients with closed head injury. Neuropsychology. 1987; $1: 7-9$.

237. Wilcox JA, Nasrallah HA. Organic factors in catatonia. $\mathrm{Br}$ J Psychiatry. 1986;149:782-84. [PMID: 3790879] DOI:10.1192/bjp.149.6.782

238. Starkstein SE, Boston JD, Robinson RG. Mechanisms of mania after brain injury. 12 case reports and review of the literature. J Nerv Ment Dis. 1988;176(2):87-100. [PMID: 3276815$]$

239. Starkstein SE, Mayberg HS, Berthier ML, Fedoroff P, Price TR, Dannals RF, Wagner HN, Leiguarda R, Robinson RG. Mania after brain injury: Neuroradiological and metabolic findings. Ann Neurol. 1990;27(6):652-59.

[PMID: 2360802] DOI:10.1002/ana.410270612 
240. Dalén P. Family history, the electroencephalogram and perinatal factors in manic conditions. Acta Psychiatr Scand. 1965;41(4):527-63. [PMID: 5884005]

DOI:10.1111/j.1600-0447.1965.tb06169.x

241. Hale MS, Donaldson JO. Lithium carbonate in the treatment of organic brain syndrome. J Nerv Ment Dis. 1982; 170(6):362-65. [PMID: 6804600] DOI:10.1097/00005053-198206000-00006

242. Pope HG Jr, McElroy SL, Satlin A, Hudson JI, Keck PE Jr, Kalish R. Head injury, bipolar disorder, and response to valproate. Compr Psychiatry. 1988;29(1):34-38.

[PMID: 3125002] DOI:10.1016/0010-440X(88)90035-1

243. Moore GJ, Bebchuk JM, Wilds IB, Chen G, Manji HK. Lithium-induced increase in human brain grey matter. Lancet. 2000;356(9237):1241-42. [PMID: 11072948] DOI:10.1016/S0140-6736(00)02793-8

244. Jamison KR. Suicide and bipolar disorder. J Clin Psychiatry. 2000;61 Suppl 9:47-51. [PMID: 10826661]

245. Van Reekum R, Cohen T, Wong J. Can traumatic brain injury cause psychiatric disorders? J Neuropsychiatry Clin Neurosci. 2000;12(3):316-27. [PMID: 10956565] DOI:10.1176/appi.neuropsych.12.3.316

246. Turnbull SJ, Campbell EA, Swann IJ. Post-traumatic stress disorder symptoms following a head injury: Does amnesia for the event influence the development of symptoms? Brain Inj. 2001;15(9):775-85. [PMID: 11516346] DOI:10.1080/02699050110034334

247. Creamer M, O’Donnell ML, Pattison P. Amnesia, traumatic brain injury, and posttraumatic stress disorder: A methodological inquiry. Behav Res Ther. 2005;43(10): 1383-89. [PMID: 16086988]

DOI:10.1016/j.brat.2004.11.001

248. Gil S, Caspi Y, Ben-Ari IZ, Koren D, Klein E. Does memory of a traumatic event increase the risk for posttraumatic stress disorder in patients with traumatic brain injury? A prospective study. Am J Psychiatry. 2005;162(5):963-69.

[PMID: 15863799]

DOI:10.1176/appi.ajp.162.5.963

249. Hibbard MR, Uysal S, Kepler K, Bogdany J, Silver J. Axis I psychopathology in individuals with traumatic brain injury. J Head Trauma Rehabil. 1998;13(4):24-39. [PMID: 9651237] DOI:10.1097/00001199-199808000-00003

250. Glaesser J, Neuner F, Lütgehetmann R, Schmidt R, Elbert T. Posttraumatic stress disorder in patients with traumatic brain injury. BMC Psychiatry. 2004;4:5.

[PMID: 15113439] DOI:10.1186/1471-244X-4-5

251. Sumpter RE, McMillan TM. Misdiagnosis of post-traumatic stress disorder following severe traumatic brain injury. Br J
Psychiatry. 2005;186:423-26. [PMID: 15863748]

DOI:10.1192/bjp.186.5.423

252. Hoge CW, McGurk D, Thomas JL, Cox AL, Engel CC, Castro CA. Mild traumatic brain injury in U.S. soldiers returning from Iraq. N Engl J Med. 2008;358(5):453-63.

[PMID: 18234750$]$

DOI:10.1056/NEJMoa072972

253. Schneiderman AI, Braver ER, Kang HK. Understanding sequelae of injury mechanisms and mild traumatic brain injury incurred during the conflicts in Iraq and Afghanistan: Persistent postconcussive symptoms and posttraumatic stress disorder. Am J Epidemiol. 2008;167(12): 1446-52. [PMID: 18424429] DOI:10.1093/aje/kwn068

254. Elzinga BM, Bremner JD. Are the neural substrates of memory the final common pathway in posttraumatic stress disorder (PTSD)? J Affect Disord. 2002;70(1):1-17. [PMID: 12113915] DOI:10.1016/S0165-0327(01)00351-2

255. Ehlers A, Clark DM. A cognitive model of posttraumatic stress disorder. Behav Res Ther. 2000;38(4):319-45. [PMID: 10761279] DOI:10.1016/S0005-7967(99)00123-0

256. Ashford JW, Miller TW. Effects of trazodone on sleep in patients diagnosed with post-traumatic disorder (PTSD). J Contemp Psychother. 1996;26(3):221-33. DOI:10.1007/BF02307588

257. Raskind MA, Peskind ER, Hoff DJ, Hart KL, Holmes HA, Warren D, Shofer J, O’Connell J, Taylor F, Gross C, Rohde K, McFall ME. A parallel group placebo controlled study of prazosin for trauma nightmares and sleep disturbance in combat veterans with post-traumatic stress disorder. Biol Psychiatry. 2007;61(8):928-34.

[PMID: 17069768]

DOI:10.1016/j.biopsych.2006.06.032

258. Ashford JW, Jarvik L. Alzheimer's disease: Does neuron plasticity predispose to axonal neurofibrillary degeneration? N Engl J Med. 1985;313(6):388-89. [PMID: 4010760]

259. Van den Heuvel C, Thornton E, Vink R. Traumatic brain injury and Alzheimer's disease: A review. Prog Brain Res. 2007;161:303-16. [PMID: 17618986] DOI:10.1016/S0079-6123(06)61021-2

260. Hall ED, Bryant YD, Cho W, Sullivan PG. Evolution of post-traumatic neurodegeneration after controlled cortical impact traumatic brain injury in mice and rats as assessed by the de Olmos silver and Fluoro-jade staining methods. J Neurotrauma. 2008;25(3):235-47.

[PMID: 18352837]

DOI:10.1089/neu.2007.0383

261. Bremner JD, Elzinga B, Schmahl C, Vermetten E. Structural and functional plasticity of the human brain in posttraumatic 
stress disorder. Prog Brain Res. 2008;167:171-86.

[PMID: 18037014]

DOI:10.1016/S0079-6123(07)67012-5

262. Mayou RA, Black J, Bryant B. Unconsciousness, amnesia and psychiatric symptoms following road traffic accident injury. Br J Psychiatry. 2000;177:540-45.

[PMID: 11102330]

DOI:10.1192/bjp.177.6.540

263. Stein DJ, Ipser JC, Seedat S. Pharmacotherapy for post traumatic stress disorder (PTSD). Cochrane Database Syst Rev. 2006(1):CD002795. [PMID: 16437445$]$

264. Krystal AD, Davidson JR. The use of prazosin for the treatment of trauma nightmares and sleep disturbance in combat veterans with post-traumatic stress disorder. Biol Psychiatry. 2007;61(8):925-27. [PMID: 17397667] DOI:10.1016/j.biopsych.2007.02.020

265. Friedman MJ. Toward rational pharmacotherapy for posttraumatic stress disorder: An interim report. Am J Psychiatry. 1988;145(3):281-85. [PMID: 2894174]

266. Pae CU, Lim HK, Peindl K, Ajwani N, Serretti A, Patkar AA, Lee C. The atypical antipsychotics olanzapine and risperidone in the treatment of posttraumatic stress disorder: A meta-analysis of randomized, double-blind, placebo-controlled clinical trials. Int Clin Psychopharmacol. 2008;23(1):1-8. [PMID: 18090502]

DOI:10.1097/YIC.0b013e32825ea324

267. Thomsen IV. Late outcome of very severe blunt head trauma: A 10-15 year second follow-up. J Neurol Neurosurg Psychiatry. 1984;47(3):260-68. [PMID: 6707671] DOI:10.1136/jnnp.47.3.260

268. Sachdev P, Smith JS, Cathcart S. Schizophrenia-like psychosis following traumatic brain injury: A chart-based descriptive and case-control study. Psychol Med. 2001; 31(2):231-39. [PMID: 11232911] DOI:10.1017/S0033291701003336

269. Fujii DE, Ahmed I. Risk factors in psychosis secondary to traumatic brain injury. J Neuropsychiatry Clin Neurosci. 2001;13(1):61-69. [PMID: 11207331] DOI:10.1176/appi.neuropsych.13.1.61

270. Fujii DA, Ahmed I, Hishinuma E. A neuropsychological comparison of psychotic disorder following traumatic brain injury, traumatic brain injury without psychotic disorder, and schizophrenia. J Neuropsychiatry Clin Neurosci. 2004;16(3):306-14. [PMID: 15377737]

DOI:10.1176/appi.neuropsych.16.3.306

271. Butler PV. Diurnal variation in Cotard's syndrome (copresent with Capgras delusion) following traumatic brain injury. Aust N Z J Psychiatry. 2000;34(4):684-87.

[PMID: 10954402]

DOI:10.1046/j.1440-1614.2000.00758.x

272. Umansky R, Geller V. Olanzapine treatment in an organic hallucinosis patient. Int J Neuropsychopharmacol. 2000;
3(1):81-82. [PMID: 11343582]

DOI:10.1017/S1461145700001723

273. Cohen-Mansfield J, Marx MS, Rosenthal AS. A description of agitation in a nursing home. J Gerontol. 1989; 44(3):M77-84. [PMID: 2715584]

274. Greve KW, Sherwin E, Stanford MS, Mathias C, Love J, Ramzinski P. Personality and neurocognitive correlates of impulsive aggression in long-term survivors of severe traumatic brain injury. Brain Inj. 2001;15(3):255-62.

[PMID: 11260773] DOI:10.1080/026990501300005695

275. Tateno A, Jorge RE, Robinson RG. Clinical correlates of aggressive behavior after traumatic brain injury. J Neuropsychiatry Clin Neurosci. 2003;15(2):155-60.

[PMID: 12724455]

DOI:10.1176/appi.neuropsych.15.2.155

276. Max JE, Robertson BA, Lansing AE. The phenomenology of personality change due to traumatic brain injury in children and adolescents. J Neuropsychiatry Clin Neurosci. 2001;13(2):161-70. [PMID: 11449023]

DOI:10.1176/appi.neuropsych.13.2.161

277. Gomez-Hernandez R, Max JE, Kosier T, Paradiso S, Robinson RG. Social impairment and depression after traumatic brain injury. Arch Phys Med Rehabil. 1997;78(12): 1321-26. [PMID: 9421985] DOI:10.1016/S0003-9993(97)90304-X

278. Rao N, Jellinek HM, Woolston DC. Agitation in closed head injury: Haloperidol effects on rehabilitation outcome. Arch Phys Med Rehabil. 1985;66(1):30-34. [PMID: 3966865$]$

279. Bogner JA, Corrigan JD, Fugate L, Mysiw WJ, Clinchot D. Role of agitation in prediction of outcomes after traumatic brain injury. Am J Phys Med Rehabil. 2001;80(9): 636-44. [PMID: 11523965] DOI:10.1097/00002060-200109000-00002

280. Elliott ML, Biever LS. Head injury and sexual dysfunction. Brain Inj. 1996;10(10):703-17. [PMID: 8879661] DOI:10.1080/026990596123972

281. Makulski DD, Taber KH, Chiou-Tan FY. Neuroimaging in posttraumatic hypopituitarism. J Comput Assist Tomogr. 2008;32(2):324-28. [PMID: 18379326] DOI:10.1097/RCT.0b013e3181636ed4

282. Cloute K, Mitchell A, Yates P. Traumatic brain injury and the construction of identity: A discursive approach. Neuropsychol Rehabil. 2008;18(5-6):651-70. [PMID: 17852757] DOI:10.1080/09602010701306989

283. Schopp LH, Good GE, Barker KB, Mazurek MO, Hathaway SL. Masculine role adherence and outcomes among men with traumatic brain injury. Brain Inj. 2006;20(11): 1155-62. [PMID: 17123932] DOI:10.1080/02699050600983735 
284. Strous R, Shoenfeld Y. To smell the immune system: Olfaction, autoimmunity and brain involvement. Autoimmun Rev. 2006;6(1):54-60. [PMID: 17110318] DOI:10.1016/j.autrev.2006.07.002

285. Kapoor N, Ciuffreda KJ. Vision disturbances following traumatic brain injury. Curr Treat Options Neurol. 2002; 4(4):271-80. [PMID: 12036500] DOI:10.1007/s11940-002-0027-z
286. Nampiaparampil DE. Prevalence of chronic pain after traumatic brain injury: A systematic review. JAMA. 2008; 300(6):711-19. [PMID: 18698069]

DOI:10.1001/jama.300.6.711

Submitted for publication September 3, 2008. Accepted in revised form May 7, 2009. 
